\title{
Influence of bed patchiness, slope, grain hiding, and form drag on gravel mobilization in very steep streams
}

\author{
Joel S. Scheingross, ${ }^{1}$ Eric W. Winchell, ${ }^{2,3}$ Michael P. Lamb, ${ }^{1}$ and William E. Dietrich ${ }^{2}$ \\ Received 30 July 2012; revised 21 March 2013; accepted 25 March 2013; published 10 June 2013.
}

[1] Steep streams are a major portion of channel networks and provide a link to transport sediment from hillslopes to lower gradient rivers. Despite their importance, key unknowns remain, perhaps foremost of which is evaluating in steep streams empirical laws for fluvial sediment transport developed for low-gradient rivers. To address this knowledge gap, we painted sediment in situ over 3 years to monitor incipient sediment motion and sediment-patch development in five small (drainage areas of $0.04-2 \mathrm{~km}^{2}$ ) and steep (slopes of 5-37\%) tributaries of Elder Creek, California, United States. We found that channel beds organized into size-sorted sediment patches which displayed active fluvial transport of gravel annually, consistent year-to-year patch median grain sizes, partial transport of bed material, and significantly higher values of critical Shields stress for incipient sediment motion compared to that observed for lower gradient rivers. The high critical Shields stresses (up to $\approx 0.5$ for the median grain size) agree within a factor of $\sim 3$ to theoretical predictions which account for slope-dependent hydraulics, grain hiding, and sediment patches. For grains of approximately the same size as the roughness length scale, slope-dependent hydraulics and bed patchiness are the dominant controls on critical Shields stress values, while grain hiding is important for grains larger or smaller than the roughness length scale. Form drag exists in our monitored tributaries but has a smaller influence than the above effects. Our field observations show fluvial processes contribute to sediment mobilization in steep channels which are often considered to be dominated by debris flows.

Citation: Scheingross, J. S., E. W. Winchell, M. P. Lamb, and W. E. Dietrich (2013), Influence of bed patchiness, slope, grain hiding, and form drag on gravel mobilization in very steep streams, J. Geophys. Res. Earth Surf., 118, 982-1001, doi:10.1002/jgrf.20067.

\section{Introduction}

[2] Sediment-transport dynamics and rates in steep streams are important for routing sediment from hillslopes to river networks [Grant et al., 1990; Montgomery and Buffington, 1997; Benda et al., 2005; Cui and Parker, 2005; Wiele et al., 2007], aquatic habitat quality [Lisle, 1989; Buffington et al., 2004; Montgomery, 2004], and landscape evolution modeling [Dietrich et al., 2003; Tucker and Hancock, 2010]. Nonetheless, the role of fluvial processes in conveying sediment through steep channels has received little study relative to lower gradient channels $(S<1 \%$, where $S$ is channel bed slope) and may differ in important ways [Comiti and Mao, 2012]. For example, in steep

\footnotetext{
${ }^{1}$ Division of Geological and Planetary Sciences, California Institute of Technology, Pasadena, California, USA.

${ }^{2}$ Department of Earth and Planetary Science, University of California, Berkeley, California, USA.

${ }^{3}$ Now at Department of Geological Sciences and Institute of Arctic and Alpine Research, University of Colorado, Boulder, USA.

Corresponding author: J. S. Scheingross, Division of Geological and Planetary Sciences, California Institute of Technology, Pasadena, CA 91125, USA. (jscheingross@caltech.edu)

(C)2013. American Geophysical Union. All Rights Reserved. 2169-9003/13/10.1002/jgrf.20067
}

streams workers have emphasized the effects of grain hiding, form drag, slope-dependent incipient-motion criterion, partial transport, and bed-sediment-size patchiness on sediment transport [e.g., Church and Hassan, 2002; Lamb et al., 2008a; Mao et al., 2008; Recking, 2009; Yager et al., 2012a; 2012b]. In addition, recent work has shown that fluvial transport in steep streams can account for a large portion of the total sediment flux [e.g., Gomi and Sidle, 2003; Mao and Lenzi, 2007; Yager et al., 2012a], yet others have argued that periodic debris flows are primarily responsible for transporting sediment in streams with slopes greater than about 10\% [e.g., Stock and Dietrich, 2003; Stock and Dietrich, 2006]. Uncertainty about the dominant processes in steep channels remains, in part, due to a paucity of field data.

[3] Accurate predictions of sediment transport in steep streams require knowledge of the conditions for incipient sediment motion, which is often calculated using a critical Shields stress $\left(\tau_{*_{c}}\right)$ [Shields, 1936]:

$$
\tau_{* c}=\frac{\tau_{c}}{\left(\rho_{s}-\rho\right) g D}
$$

where $\tau_{c}$ is the bed shear stress at incipient motion, $\rho_{\mathrm{s}}$ is the density of sediment, $\rho$ is the density of water, $g$ is acceleration due to gravity, and $D$ is particle diameter. In lowgradient gravel-bed rivers, a constant value of $\tau_{*_{c}} \approx 0.045$ has been shown to accurately predict the conditions for sediment motion [e.g., Buffington and Montgomery, 1997]. 
In steep streams (e.g., $S>5 \%$ ), however, a constant value of $\tau *_{c}$ may not be appropriate. For example, some theoretical models for incipient sediment motion predict $\tau_{*_{c}}$ decreases with slope due to the increased component of gravity in the downstream direction [e.g., Wiberg and Smith, 1987]. Yet, flume data at slopes up to $47 \%$ show that critical Shields stresses increase with channel gradient [e.g., Ashida and Bayazi, 1973; Mizuyama, 1977; Bathurst et al., 1984; Prancevic et al., 2011]. Field data on incipient motion are limited for streams with $S>5 \%$ but also show an increase in critical Shields stress with increasing slope up to $S=14 \%$ [e.g., Mueller et al., 2005; Lenzi et al., 2006; Mao and Lenzi, 2007; Mao et al., 2008]. Recent models show that the critical Shields stress may increase with channel slope due to changes in local flow velocity and turbulent fluctuations as the flow depth to grain size ratio decreases [Lamb et al., 2008a; Recking, 2009]. Others suggest that increased form drag due to the presence of immobile morphologic structures results in larger $\tau_{*_{c}}$ with increasing channel slope [e.g., Buffington and Montgomery, 1999; Nitsche et al., 2011; Ferguson, 2012; Yager et al., 2012a].

[4] Predicting incipient motion and bedload transport in steep channels is further complicated by the organization of the channel bed into distinct sediment patches [e.g., Paola and Seal, 1995; Dietrich et al., 2006; Yager et al., 2012b]. Patches are sediment-size-sorted areas on the bed which likely form through feedbacks between bed topography, shear stress distribution, and sediment transport [Nelson et al., 2009; Nelson et al., 2010]. For example, Yager et al. [2012a] showed that standard models for bedload transport developed in low-gradient streams over-predict transport rates by an order of magnitude in steep streams $(S=9.8-17 \%)$ because the models did not account for patches of immobile grains. Since the critical Shields stress is sensitive to the ratio of grain size to the local bed roughness [Wiberg and Smith, 1987], the presence of patches has led workers to argue that patches with different grain-size distributions within the same river reach are mobilized at different bed shear stresses [e.g., Paola and Seal, 1995]. The mobilization of relatively finer patches at lower bed shear stresses leads to reach-wide partial transport of sediment (i.e., a portion of the grain-size distribution present on the channel bed is absent in the bedload) [Paola and Seal, 1995; Yager et al., 2012b]. While some have argued that grains within a single patch are all mobilized at the same critical shear stress [Paola and Seal, 1995], field data from steep streams suggests individual patches experience partial transport, with a preference for mobilizing finer grains [Yager et al., 2012b]. At the individual particle scale, grain mobilization is a function of both the grain weight and grain size relative to roughness on the bed. Relatively coarse grains weigh more than fine grains but also protrude further from the bed and are thus subject to increased drag and lower friction angles [e.g., Einstein, 1950; Egiazaroff, 1965; Wiberg and Smith, 1987; Kirchner et al., 1990]. These competing effects, termed grain hiding, likely influence the mobilization of distinct grain sizes from individual patches.

[5] In steep streams, accurate incipient-motion predictions likely require quantification of the extent of bed patchiness, grain hiding, form drag, and slope-dependent hydraulics. There is a general paucity of data on critical Shields stress for channels with $S>5 \%$, and no study has attempted to quantify the influence of patchiness, grain hiding, form drag, and slope-dependent hydraulics together in a field setting. This lack of data has led many modelers to treat steep channels with the same semi-empirical expressions (e.g., $\tau_{*_{c}} \approx 0.045$ ) developed for lower gradient gravel-bed rivers [Sklar and Dietrich, 2004; Whipple, 2004; Lamb et al., 2008b; Tucker and Hancock, 2010; Tsai et al., 2012].

[6] Here we present results from monitoring sediment mobilization via painting sediment patches and tracking the movement of individual grains in five steep $(S=5-37 \%)$ tributary reaches of Elder Creek, California, United States. We use our monitoring data to calculate critical Shields stresses and to quantify the effects of bed patchiness, grain hiding, form drag, and slope-dependent hydraulics via comparison to theory that allows isolation of these variables. In this paper, we first introduce the study area and describe the study reaches. Second, we present methods on monitoring hydraulics and sediment transport, including surveying channel geometry, field measurements of flow hydraulics, modeling bed shear stress with a non-uniform flow algorithm, and documenting grain mobilization via repeat surveys of marked tracer particles and patches. Third, we discuss results from monitoring, including measured flow discharges and velocities, grain mobilization from patches, and travel distances of marked particles. Fourth, we present analysis of our data to calculate form drag and critical Shields stresses, and examine controls on incipient motion. Finally, we discuss the implications of our analysis for predicting grain entrainment and sediment transport in steep streams.

\section{Study Area and Monitored Tributaries}

[7] Elder Creek is a small (drainage area of $16.8 \mathrm{~km}^{2}$ ) tributary of the South Fork Eel River located in northern California, United States (Figure 1). The stream hosts a U.S. Geological Survey hydrologic benchmark station near its mouth with continuous discharge records from 1967 to 2013. The local lithology consists of interbedded arkosic sandstone and argillite of the Coastal Franciscan Belt [Jayko et al., 1989]. The area has a Mediterranean climate with annual average precipitation of approximately $\sim 2 \mathrm{~m} / \mathrm{yr}$, the vast majority of which falls as rain between the months of December and March [Mast and Chow, 2000]. Elder Creek watershed is located entirely within the University of California's Angelo Coast Range Reserve and has been free of grazing, logging, mining, and other disturbances since 1959 (the basin had only limited logging during the late nineteenth and early twentieth centuries) [Mast and Chow, 2000]. While there are no records of modern debris flows within the catchment, debris flows have been active in the area in the Holocene [Scheingross et al., 2008], and many tributaries are incised into debris flow fans near their junction with the main stem of Elder Creek. Cosmogenic dating of modern stream sediment yields basin average erosion rates for Elder Creek of $0.16-0.18 \mathrm{~mm} / \mathrm{yr}$ [Fuller et al., 2009].

[8] We monitored five tributaries of Elder Creek over three water years from September 2007 to July 2010. In order to examine effects of slope and roughness on sediment motion, we chose reaches spanning a range of channel gradients from 5 to $37 \%$ and median particle diameters of 57 to $155 \mathrm{~mm}$. These reaches range in 


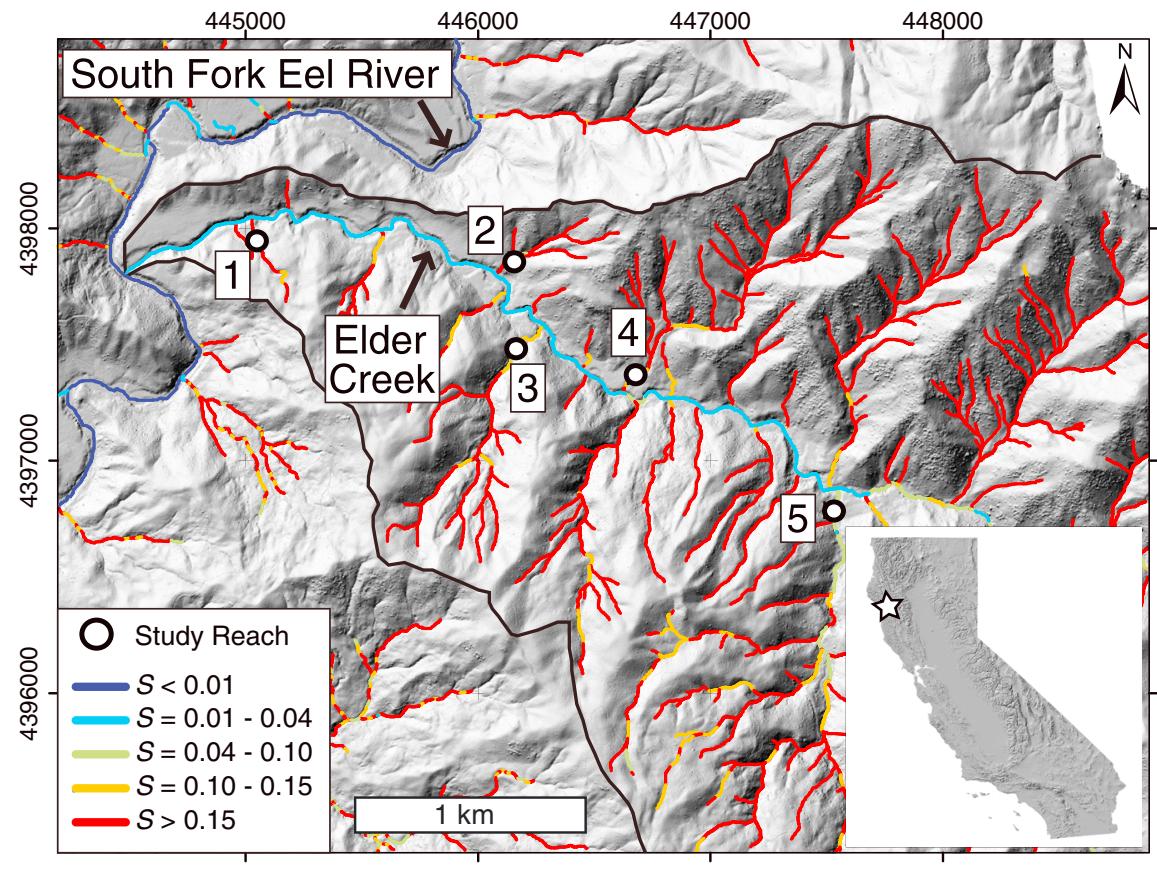

Figure 1. Airborne laser swath mapping $\left(1 \mathrm{~m}^{2}\right.$ resolution) derived shaded relief map showing the Elder Creek watershed and the location of the five tributary reaches studied (white circles with numbered boxes). The stream network is color coded by channel slope $(S)$ calculated over channel lengths with $10 \mathrm{~m}$ change in elevation; note the vast majority of the channel network exists at slopes greater than $15 \%$. UTM coordinates are displayed along figure borders. Inset shows outline of California with star indicating approximate location of the study site.

drainage area from 0.04 to $2 \mathrm{~km}^{2}$, bankfull depths from 0.13 to $0.3 \mathrm{~m}$, and bankfull widths from 1.1 to $4.1 \mathrm{~m}$ (Figures 1 and 2 and Table 1). Study reaches 2 and 4 are located in channels near the apex of debris flow fans which are deposited over a strath terrace of Elder Creek; the other reaches $(1,3$, and 5) are located in channelized valleys. For each tributary, we selected short, straight reaches $(\sim 20-50 \mathrm{~m}$ in length) for monitoring. All monitored reaches were mantled with coarse sediment, including boulders. There is no exposure of bedrock in the channel beds within any of the study reaches, and bedrock channel beds are rarely exposed in the Elder Creek tributaries in general. Sediment on the surface of monitored reaches is organized into distinct size-sorted patches. The steepest channels examined here (reaches 1 and 2, slopes of $37 \%$ and $18 \%$, respectively) have a cascading morphology (in the sense of Montgomery and Buffington [1997]) and include isolated areas of soil development and leaf litter accumulation within channels (Figures 2a and 2b); lower gradient channels have more pronounced step-pool morphology but also include short cascading reaches (Figures 2c, 2d, and 2e).

\section{Methods}

[9] Calculating critical Shields stresses for gravel entrainment in steep streams requires characterization of channel geometry, flow hydraulics, bed roughness, and sediment transport. In this section, we first describe our methods to survey channel geometry and grain-size distributions. Next we discuss our methods for measuring flow hydraulics and calibrating a flow algorithm to estimate bed shear stress. Finally we describe our methods for documenting sediment transport.

\subsection{Channel Geometry}

[10] We surveyed channel geometry with high-resolution ground-based light detection and ranging (LiDAR) in reaches 2 and 4 ; in the remaining three reaches, we surveyed longitudinal profiles and cross-sections with a stadia rod and hand level. Points along longitudinal profiles were surveyed at high densities to capture breaks in slope due to steps, pools, and other structures. Despite large changes in local slope along a longitudinal profile, channel cross-sectional shape remained fairly constant over several meters (Figure 2); therefore, we spaced cross-section surveys approximately every $2 \mathrm{~m}$ in reaches 1 and 3 and every $4 \mathrm{~m}$ in reach 5 .

\subsection{Flow Hydraulics}

[11] We measured stream discharge and reach average velocity for six flow events in reaches 2 and 4 (Table 2) using the salt dilution method, whereby salt is injected into a stream as a tracer and discharge is estimated assuming conservation of the tracer mass [Elder et al., 1990; Hudson and Fraser, 2005]. This method is advantageous over the traditional slug-injection method as it yields the same results for injection of both dry salt and salt dissolved into solution. For each measurement, we injected salt at a distance of 7 to 10 channel widths upstream of a conductivity meter. This length scale is near the low end of observed mixing lengths in mountain streams [Day, 1977a] and was chosen to avoid large pools and backwater areas where water could stagnate 


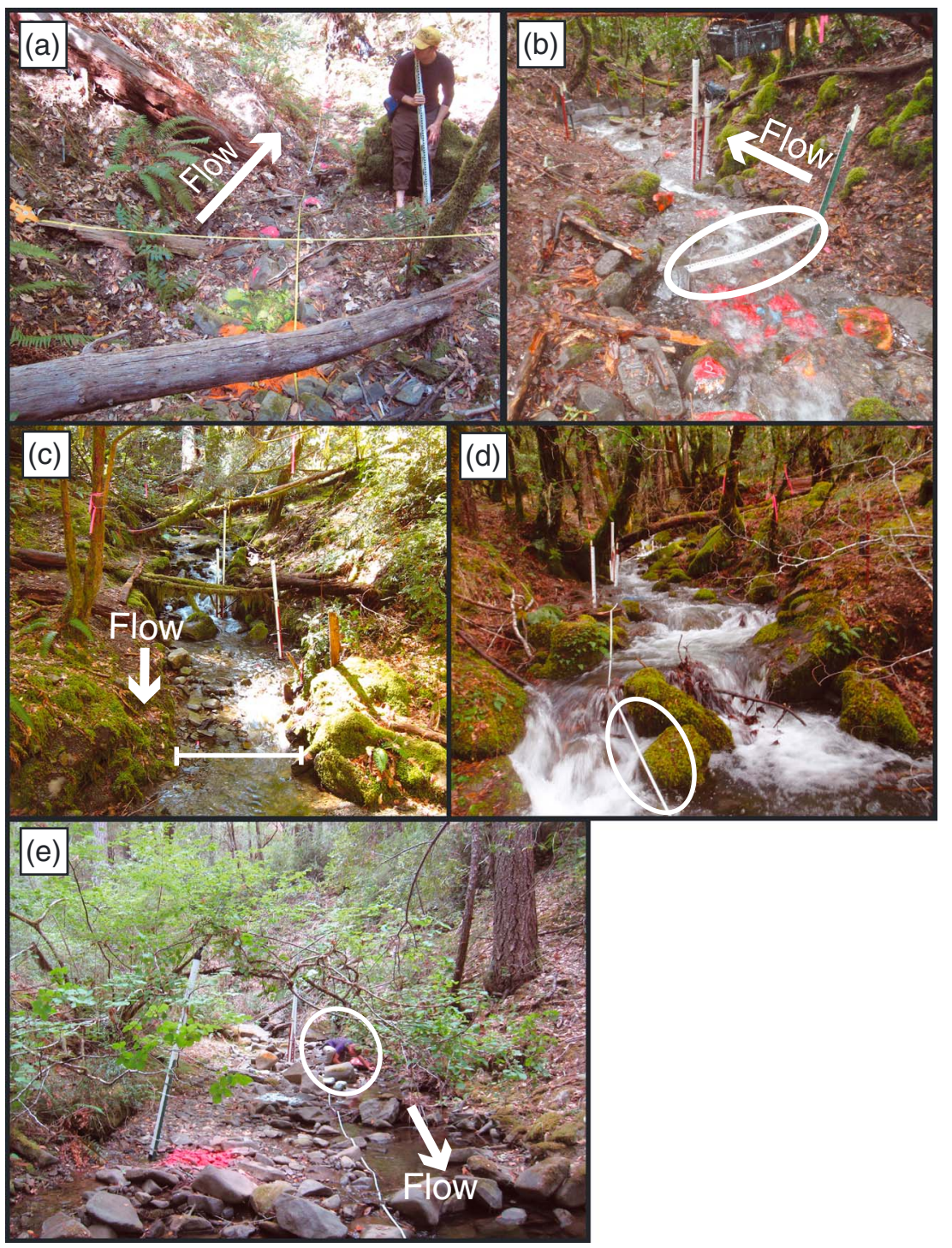

Figure 2. Field photographs of study reaches. (a) Reach 1; (b) reach 2, circled staff gage is $1 \mathrm{~m}$ long; (c) reach 3 , channel width indicated by white line in foreground is $\sim 2 \mathrm{~m}$; (d) reach 4 , note circled $1.2 \mathrm{~cm}$ wide white measuring tape stretched parallel to stream for scale; and (e) reach 5 (Misery Creek), note person (circled, crouching) for scale. Figures $2 \mathrm{~b}$ and $2 \mathrm{~d}$ show near bank full conditions. Vertical, white PVC pipes house pressure transducers and crest stage gages measuring water depth.

and compromise the reliability of the measurement [Elder et al., 1990; Moore, 2003]. A single conductivity probe was placed at the center of the channel, and we manually recorded stream conductivity ensuring a minimum of 25 measurements to accurately characterize the passing salt wave [Day, 1977b]. Conductivity was converted to salt concentration using a laboratory-measured calibration coefficient in stream water. We additionally calculated reach-averaged stream velocity

Table 1. Reach-Averaged Hydraulic Geometry and Basic Characteristics of Monitored Reaches ${ }^{\mathrm{a}}$

\begin{tabular}{|c|c|c|c|c|c|c|c|c|}
\hline Reach & $\begin{array}{l}\text { Drainage Area } \\
\left(\mathrm{km}^{2}\right)\end{array}$ & $\begin{array}{l}\text { Local Slope } \\
(\%)\end{array}$ & $\begin{array}{l}\text { Bankfull Depth } \\
(\mathrm{m})\end{array}$ & $\begin{array}{l}\text { Bankfull Width } \\
(\mathrm{m})\end{array}$ & $\begin{array}{l}D_{16} \\
(\mathrm{~mm})\end{array}$ & $\begin{array}{l}D_{50} \\
(\mathrm{~mm})\end{array}$ & $\begin{array}{l}D_{84} \\
(\mathrm{~mm})\end{array}$ & $\begin{array}{c}D_{84 \text {-mobile }} \\
\text { (mm) }\end{array}$ \\
\hline 1 & 0.04 & 37 & 0.13 & 1.1 & 10 & 57 & 133 & 45 \\
\hline 2 & 0.12 & 18 & 0.15 & 1.5 & 21 & 97 & 279 & 145 \\
\hline 3 & 0.55 & $7^{\mathrm{b}}$ & 0.15 & 3.5 & 15 & 101 & 286 & 143 \\
\hline 4 & 0.84 & 9 & 0.30 & 4.1 & 23 & 155 & 446 & 197 \\
\hline 5 (Misery Creek) & 2.0 & 5 & 0.28 & 3.5 & 11 & 72 & 201 & 90 \\
\hline
\end{tabular}

\footnotetext{
${ }^{\mathrm{a}} D_{16}, D_{50}$, and $D_{84}$, are the 16th, median, and 84th percentile grain sizes, respectively, for reach-averaged pebble counts (including steps and immobile
} grains). $D_{84-m o b i l e}$ is the 84 th percentile grain size for reach-averaged pebble counts of mobile sediment.

${ }^{\mathrm{b}}$ This reach features a $\sim 1 \mathrm{~m}$ alluvial step. The local slope below the step is $5 \%$, and the local slope above the step is $9 \%$. 
Table 2. Reach-Averaged Flow Hydraulic Measurements ${ }^{\mathrm{a}}$

\begin{tabular}{ccccc}
\hline Reach & Date & Discharge $\left(\mathrm{m}^{3} / \mathrm{s}\right)$ & $U(\mathrm{~m} / \mathrm{s})$ & $\mathrm{h}(\mathrm{m})$ \\
\hline 2 & 17 Feb 2009 & 0.0006 & 0.033 & 0.03 \\
2 & 23 Feb 2009 & 0.014 & 0.19 & 0.085 \\
2 & 24 Feb 2009 & 0.030 & 0.25 & 0.09 \\
2 & 3 Mar 2009 & 0.013 & 0.16 & 0.08 \\
4 & 24 Feb 2009 & 0.19 & 0.32 & 0.21 \\
4 & 3 Mar 2009 & 0.14 & 0.19 & - \\
\hline
\end{tabular}

${ }^{\mathrm{a}} U$ and $h$ are measured reach-averaged flow velocity and flow depth, respectively. Measurements made on 24 February 2009 represent near bankfull discharge.

based on the travel time from salt injection to the center of mass of the passing salt wave (i.e., the "centroid velocity" [Calkins and Dunne, 1970]).

[12] For one discharge measurement (reach 2, 17 February 2009), we recorded the time of peak conductivity following salt injection but did not make sufficient manual conductivity measurements to accurately characterize the shape of the passing salt wave. For this reach only, we calculated reachaveraged velocity using the time from salt injection to peak conductivity (i.e., the "peak velocity" of Calkins and Dunne [1970]) and estimated discharge in the reach as $Q=U w h$, where $Q$ is water discharge, $U$ is reach-averaged flow velocity, and $w$ and $h$ are reach-averaged width and flow depth, respectively, measured in the field.

[13] In addition to measurements of flow hydraulics, we instrumented each study reach with a pressure transducer measuring atmospheric and total (atmospheric plus water) pressure at $15 \mathrm{~min}$ intervals and a crest stage gage (placed adjacent to the pressure transducer and built to U.S. Geological Survey standards [Holmes et al., 2001]) to measure peak water stage. These instruments allowed estimation of flow hydraulics for periods when we were unable to make manual measurements.

\subsection{Modeling Bed Shear Stress}

[14] In low-gradient streams, bed shear stress is often estimated assuming steady, uniform flow (i.e., $\tau=\rho g R S$, where $\tau$ is bed shear stress and $R$ is the hydraulic radius); however, these assumptions may be invalid in the steep streams examined here which have flow cascading over steps and chutes.
Instead, we used a non-uniform flow algorithm, HEC-RAS (Hydrologic Engineering Center River Analysis System, available at http://www.hec.usace.army.mil/software/hecras/), to estimate bed shear stress. HEC-RAS has been used successfully by others in channels with $S>1 \%$ [e.g., Church and Hassan, 2002; Thompson and Croke, 2008] and is convenient to use as it can model transcritical flow. HECRAS should be used with caution for $S>10 \%$ (reaches 1 and 2) where the gradually varied flow and hydrostatic assumptions used in the model may be invalid (U.S. Army Corps of Engineers, 2010, pg. 2-20 to 2-21); however, available codes for rapidly varying, nonhydrostatic flows do not exist, to our knowledge. Here we describe the procedures for calibration of our flow algorithm with manually measured flow depths, velocities, and discharges.

[15] Channel geometry for HEC-RAS was taken from our field surveys where each survey point in the long profile was used as a node (i.e., cross-section) within the model (Figure 3). In reaches 1, 3, and 5, we did not survey a cross-section at each node within the longitudinal profile and instead used the surveyed cross-section associated with the nearest node as the input to HEC-RAS based on our observation that variations in cross-section geometry was small over the scale of $\sim 2-4 \mathrm{~m}$ compared to changes in river-bed elevation. This resulted in a high density of nodes within HEC-RAS sufficient to capture steps and other breaks in slope which affect flow hydraulics (Figure 3 and Table 3). For all modeling, we set the upstream and downstream boundary conditions to critical depth based on the observations of steps and overspilling flow [e.g., Rouse, 1936]. We then iterated with changing the flow resistance (i.e., Manning's $n$ ) to minimize the misfit between our manually measured flow depths and HEC-RAS predicted flow depths (Figure 3), with all other parameters set to their default values (e.g., expansion and contraction coefficients set to 0.3 and 0.1 , respectively).

[16] We estimated the critical shear stress for sediment transport from patches assuming sediment was mobilized at the peak flow prior to sediment recovery. HEC-RAS parameter settings were the same as described above (i.e., critical upstream and downstream boundary conditions, and all other parameters set to default values). We iterated with changing both discharge and Manning's $n$ in HEC-RAS until modeled flow depths matched (within 5\%) flow depths
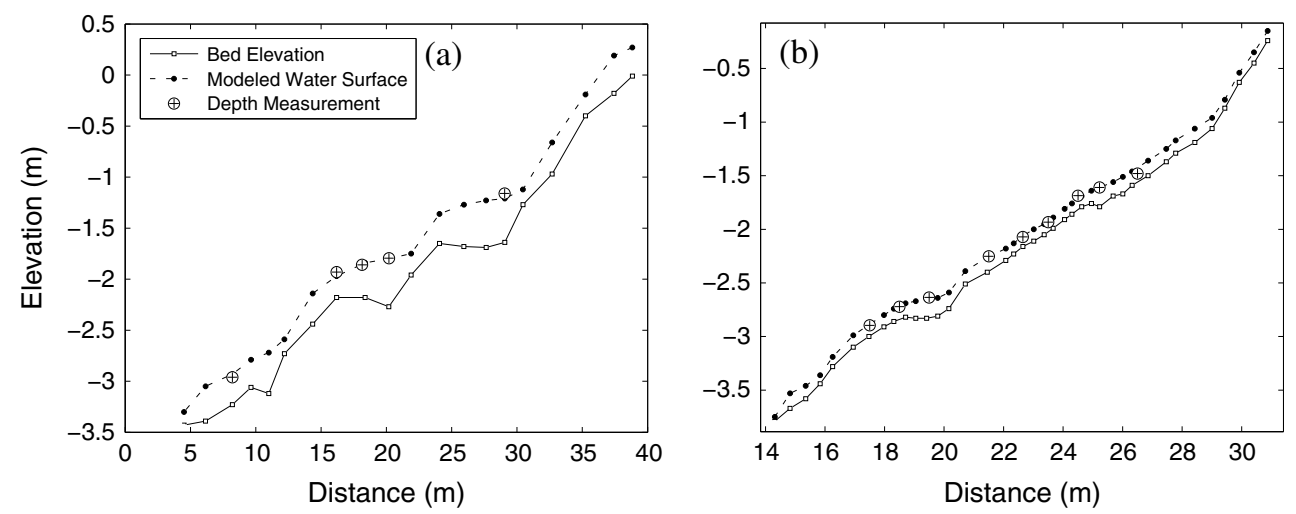

Figure 3. Comparison of modeled water surface to flow-depth measurements. HEC-RAS modeling for the (a) 3 March 2009 event in reach 2 and (b) the 24 February 2009 event in reach 4. See Table 2 for manual flow measurements in each event. 
Table 3. Spacing of HEC-RAS Channel Geometry

\begin{tabular}{ccccc}
\hline Reach & $\begin{array}{c}\text { Modeled Reach } \\
\text { Length }(\mathrm{m})\end{array}$ & $\begin{array}{c}\text { Number of Longitudinal } \\
\text { Profile Nodes }\end{array}$ & $\begin{array}{c}\text { Number of Unique } \\
\text { Surveyed Cross-sections }\end{array}$ & $\begin{array}{c}\text { Average Node } \\
\text { Spacing }(\mathrm{m})\end{array}$ \\
\hline 1 & 16.4 & 30 & 8 & 0.55 \\
2 & 16.6 & 39 & 39 & 0.43 \\
3 & 16.1 & 18 & 20 & 0.89 \\
4 & 34.3 & 20 & 7 & 1.72 \\
5 (Misery Creek) & 19.8 & 16 & 24 \\
\hline
\end{tabular}

measured with stage recorders and the predicted Manning's $n$ matched the Darcy-Weisbach friction factor, $f$, predicted by Ferguson [2007] (where $f$ and Manning's $n$ can be related by definition by $n=\left[R^{2 / 3} S^{1 / 2}\right] /\left[u_{*}(8 / f)^{1 / 2}\right]$, and $u_{*}$ is the reachaveraged shear velocity defined as $\left.u_{*}=(\tau / \rho)^{0.5}\right)$. For all cases but patch 1a in reach 1, local stress was estimated from the cross-section nearest the patch of interest. For patch 1a in reach 1 (the steepest reach, $S=37 \%$ ), the flow was cascading between two cross-sections with locally changing channel gradient. Due to the complex flow for this case, we report the shear stress for both bounding cross-sections as a measure of possible variability.

\subsection{Monitoring Sediment Transport}

[17] Within each reach, we selected individual sedimentsize-sorted patches to monitor for grain mobilization and marked patches (via spray painting) in place. Patches were typically $\sim 0.5$ by $0.5 \mathrm{~m}$ in areal extent, and we attempted to select patches with apparently mobile sediment, avoiding areas of the bed with lichen development or strongly interlocked grains. For reaches 1-4, we selected patches within the channel thalweg in order to minimize the influence of cross-channel variations in flow due to bars, wall drag, and other morphologic structures. Furthermore, we avoided pools or other areas subject to plunging flow and secondary currents. Perennial flow in reach 5 made it impossible to paint patches in situ within the thalweg; instead we painted emerged patches as close to the thalweg as possible at the end of summer when flow depth was lowest.

[18] To compare transport of mobile gravel in active patches to reach-wide transport, we additionally marked (via spray painting) an average of 10 individual cobbles and boulders per reach, spanning a range of intermediate grain diameters $(D=90$ to $450 \mathrm{~mm})$. Repeat photographs of cobble and boulder position were used to determine mobilization of these larger grains.

Table 4. Transport Data for Patches in Specific Sediment-Transport Events ${ }^{\mathrm{a}}$

\begin{tabular}{|c|c|c|c|c|c|c|c|c|}
\hline Reach & Patch & Storm & $D_{1 \text { meter }}(\mathrm{mm})$ & $D_{\max }(\mathrm{mm})$ & $\begin{array}{c}\text { Number of } \\
\text { Grains Recovered }\end{array}$ & $\begin{array}{l}\text { Number of Grains } \\
<1 \mathrm{~m} \text { from Patch }\end{array}$ & $k_{s}(\mathrm{~mm})$ & $\tau_{\max }(\mathrm{Pa})$ \\
\hline 1 & $1 \mathrm{a}$ & Winter $2007 / 2008$ & 37 & 54 & 127 & 49 & 15.9 & 178 \\
\hline 1 & $1 \mathrm{a}$ & 24 Feb 2009 & 7 & 10 & 28 & 27 & 12.5 & 329 \\
\hline 1 & $1 \mathrm{a}$ & Winter $2009 / 2010$ & 21 & 30 & 15 & 15 & 11.5 & 194 \\
\hline 2 & $2 \mathrm{a}$ & Winter $2007 / 2008$ & 38 & 112 & 100 & 15 & 50.2 & 124 \\
\hline 2 & $2 \mathrm{a}$ & 24 Feb 2009 & 18 & 19 & 11 & 11 & 30.4 & 95 \\
\hline 2 & $2 \mathrm{a}$ & Winter $2009 / 2010$ & - & 20 & 10 & 0 & 38.3 & 106 \\
\hline 2 & $2 b$ & Winter $2007 / 2008$ & 61 & 90 & 90 & 7 & 36.7 & 203 \\
\hline 2 & $2 b$ & 25 Dec 2008 & 21 & 25 & 19 & 19 & 50.3 & 108 \\
\hline 2 & $2 b$ & 24 Feb 2009 & 89 & 115 & 125 & 44 & 50.3 & 172 \\
\hline 2 & $2 b$ & Winter $2009 / 2010$ & - & 110 & 58 & 5 & 52.4 & 185 \\
\hline 3 & $3 a$ & Winter $2007 / 2008$ & - & 76 & 114 & 3 & 25.1 & 104 \\
\hline 3 & $3 a$ & 14 Nov 2008 & 14 & 20 & 27 & 27 & 33.6 & 12 \\
\hline 3 & $3 a$ & 25 Dec 2008 & 19 & 30 & 116 & 79 & 33.6 & 19 \\
\hline 3 & $3 a$ & 24 Feb 2009 & 57 & 70 & 126 & 13 & 33.6 & 28 \\
\hline 3 & $3 a$ & Winter $2009 / 2010$ & - & 52 & 51 & 0 & 25.0 & 52 \\
\hline 3 & $3 c$ & Winter $2007 / 2008$ & - & 72 & 26 & 4 & 58.8 & 119 \\
\hline 3 & $3 c$ & 25 Dec 2008 & 16 & 20 & 8 & 8 & 62.7 & 30 \\
\hline 3 & $3 c$ & 24 Feb 2009 & 26 & 45 & 109 & 100 & 62.7 & 39 \\
\hline 3 & $3 c$ & Winter $2009 / 2010$ & - & 48 & 60 & 1 & 40.2 & 65 \\
\hline 4 & $4 a$ & Winter $2007 / 2008$ & - & 25 & 8 & 1 & 64.1 & 204 \\
\hline 4 & $4 \mathrm{a}$ & 24 Feb 2009 & 11 & 90 & 79 & 57 & 85.6 & 176 \\
\hline 4 & $4 a$ & Winter $2009 / 2010$ & - & 40 & 9 & 2 & 53.4 & 209 \\
\hline 5 & $5 \mathrm{a}$ & Winter $2007 / 2008$ & - & 48 & 10 & 0 & 38.6 & 93 \\
\hline 5 & $5 \mathrm{a}$ & 24 Feb 2009 & 24 & 35 & 48 & 29 & 33.3 & 47 \\
\hline 5 & $5 \mathrm{a}$ & Winter $2009 / 2010$ & - & 32 & 3 & 0 & 34.5 & 82 \\
\hline 5 & $5 b$ & Winter $2007 / 2008$ & 33 & 45 & 51 & 10 & 14.1 & 53 \\
\hline 5 & $5 b$ & 24 Feb 2009 & 22 & 30 & 71 & 11 & 13.5 & 21 \\
\hline 5 & $5 b$ & Winter $2009 / 2010$ & - & 130 & 11 & 3 & 19.4 & 44 \\
\hline
\end{tabular}

${ }^{\mathrm{a}} D_{1 \text { meter }}$ is the mean grain size of the recovered tracer particles deposited within $1 \mathrm{~m}$ downstream of the patch, where "-" indicates five or less grains were collected within $1 \mathrm{~m}$ of the patch and $1 \mathrm{~m}$ estimates were not made. $D_{\max }$ is maximum grain size recovered from a given patch in a given storm event. $k_{s}$ is the geometric mean grain size of the patch from where moved grains originated. $\tau_{\max }$ is HEC-RAS calculated peak shear stress used in calculating critical Shields stress. Listing of individual storm dates (e.g., 24 Feb 2009) indicates measurements were made for a specific storm event. Listing of a season (e.g., Winter 2007/2008) indicates measurements integrate multiple storm events over an entire season, with the peak observed discharge event assumed to have transported all the sediment. 


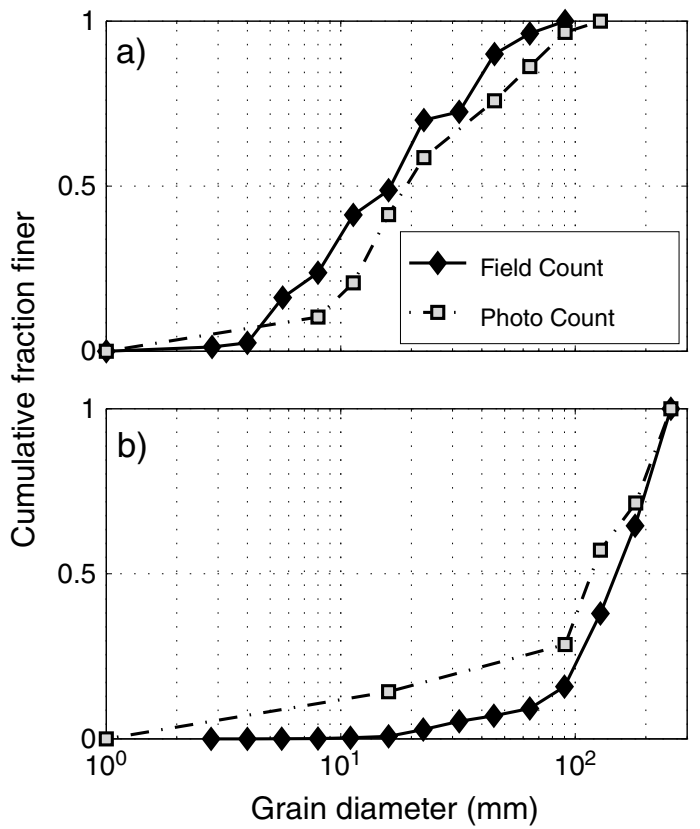

Figure 4. Comparison of field- and photo-based gridby-number pebble counts for (a) reach 5 , patch 5 b and (b) reach 4 , patch $4 \mathrm{a}$. Median grain sizes generally agree within less than a factor of 2 , and there is no systematic bias toward overpredicting or underpredicting grain-size distributions with the photograph-based method. Differences in manual and photograph counts should be expected as the exact grains counted in each method were not the same, and the use of a grid-by-number method over a small area limits the total number of grains counted.

[19] We monitored sediment motion over three field seasons. Mobilized grains from painted patches served as particle tracers and were recovered when found during and after storm events, allowing measurements of the particle distance traveled and diameters of mobilized particles. During the 2008/2009 winter, we made field visits to document sediment motion before, after, and during every storm. In the other two seasons of monitoring, our results came from field measurements made at the end of the rainy season (Table 4).

[20] We measured the grain-size distribution of painted patches using photographs. This allowed us to measure particle sizes without disturbing the position of grains on the bed. We employed a grid-by-number approach and set grid spacing equal to the maximum grain size present within the painted patch, which gives results similar to bulk-volume measurements [Bunte and Abt, 2001]. Given the small areal extent of the patch $\left(\sim 0.25 \mathrm{~m}^{2}\right)$ and large grains (up to $150 \mathrm{~mm}$ ), the total number of particles per count averaged $\sim 25$ grains. We measured the short axis of particles and multiplied the axis length by a factor of 1.07 to account for the fact that the true median axis is not always exposed in the photographic image [Bunte and Abt, 2001]. Grain-size distributions for photographic pebble counts were comparable with field measurements of particle intermediate axes made using the grid-by-number method for select patches (Figure 4). We additionally measured reach-averaged grain-size distribution spanning the full channel reach (including steps and immobile grains within the bed) using grid-by-number sampling of 100-200 grains per reach (Table 1).

[21] Recovery of painted tracer particles from patches was limited by burial of grains, potential loss downstream where tributaries join Elder Creek, wearing away of paint, and the fact that painting in situ did not allow marking the underside of grains. We counted the painted grain-number density from photographs taken immediately after spray painting (i.e., before transport), and measured the patch area absent of painted grains from photographs taken the following summer after transport had ceased to estimate the number of transported grains (Figure 5). We compared this estimate with the total number of recovered grains (Table 4) to calculate percent recovery from a patch for a given water year. For cases where aggradation occurred within a patch, this method underestimates the true recovery rate; thus, recovery percents reported here are minimum estimates. Recovery rates varied from approximately 2 to $85 \%$; low recovery rates were generally associated with fine patches that experienced significant mobility (and hence were more prone to burial and loss downstream).

\section{Field Monitoring Results}

[22] In this section, we report field results on flow hydraulics and sediment transport. Sediment-transport results are reported in two subsections including painted-patch grainsize evolution and particle travel distance. The flow hydraulic and sediment-transport data presented here are used to calculate critical Shields stress for grain entrainment in section 5.

\subsection{Flow Hydraulics}

[23] Flow in all study reaches responded to winter storms (Figure 6). Two of the five tributaries had ephemeral flow (reaches 1 and 2, which experienced flow lasting hours to days following storms but no sustained winter base flow), two showed intermittent flow (reaches 3 and 4, which experienced winter base flow for the majority of the rainy season), and one had perennial flow (reach 5). For the ephemeral and intermittent streams, flow events were generally longer and had larger peak-stage heights at the end of the winter season rather than the beginning. This is likely due to flow events early in the winter season raising the groundwater table and (for the intermittent streams) creating winter base flow.

[24] Peak discharges during the study period were relatively modest (the largest flood occurred in the 2007/2008 winter with a recurrence interval of 1.8 years on Elder Creek). Measured peak discharges ranged from $0.03 \mathrm{~m}^{3} / \mathrm{s}$ for reach 2 to $0.19 \mathrm{~m}^{3} / \mathrm{s}$ for reach 4 (Table 2). Measured peak reach-averaged velocity was 0.25 and $0.32 \mathrm{~m} / \mathrm{s}$ and reachaveraged flow depth was 8.5 and $21 \mathrm{~cm}$ for reaches 2 and 4 , respectively. These flow depths are of similar magnitude to the measured reach-averaged median grain size (Table 1), and both mobile and immobile particles were often emergent from the flow at peak discharge (Figure 2b).

[25] We evaluated the performance of our HEC-RAS modeling by comparing the modeled water surface elevation to observed water surface elevations (Figure 3) and by comparing the ratio of $U / u *$ to $f$ predicted by Ferguson [2007] 


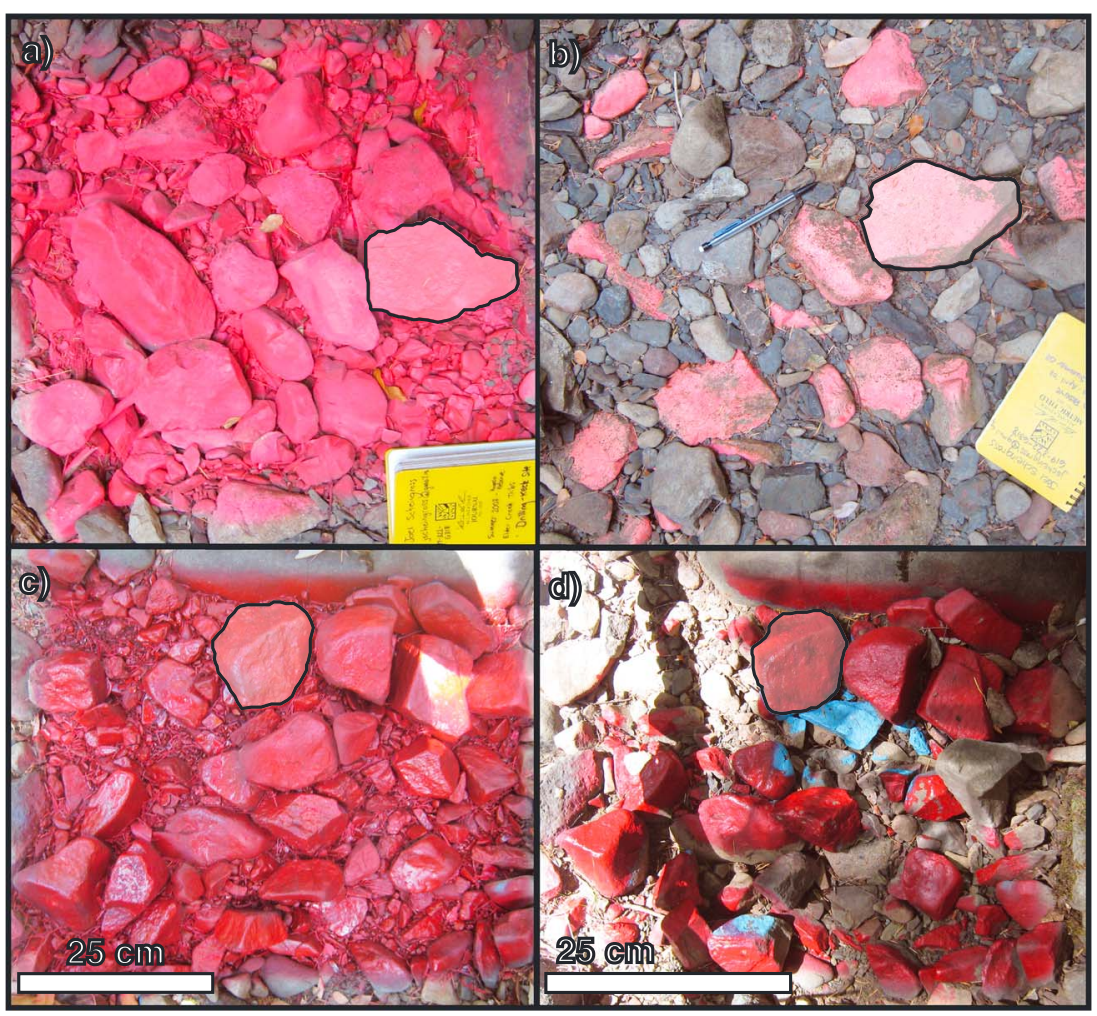

Figure 5. Patch $3 a$ (reach 3) immediately after spray painting in (a) summer 2007 and (b) summer 2008 after 1 year of fluvial transport. Patch $2 b$ (reach 2) in (c) summer 2008 and (d) summer 2009. Blue grains in Figure 5d were painted in summer 2007, buried in winter 2007/2008, and then re-exposed in winter $2008 / 2009$. Flow is left to right in all images. Yellow notebooks in Figures $5 \mathrm{a}$ and $5 \mathrm{~b}$ are $\sim 18 \mathrm{~cm}$ in length, white scale bars are $\sim 25 \mathrm{~cm}$ in length in Figures $5 \mathrm{c}$ and $5 \mathrm{~d}$. Black outlined and highlighted grains show a single unmoved grain to help visually orient between photos.

$$
\frac{U}{u_{*}}=\left(\frac{8}{f}\right)^{1 / 2}=\frac{a_{1} a_{2}\left(R / D_{84}\right)}{\left[a_{1}^{2}+a_{2}^{2}\left(R / D_{84}\right)^{(5 / 3)}\right]^{(1 / 2)}}
$$

where $a_{1}=6.5, a_{2}=2.5$ as suggested by Ferguson [2007], and $D_{84}$ is the grain size for which $84 \%$ of the reach-wide bed is finer. We found reasonable agreement between $U / u_{*}$ and $R / D_{84}$ (Figure 7 ), suggesting that HEC-RAS accurately captures flow hydraulics and that $f$ increases with decreased flow depth to roughness ratios for the streams in which we measured discharged. HEC-RAS modeled values of reachaveraged hydraulic radius, velocity, and bed shear stress, ranged from 0.05 to $0.34 \mathrm{~m}, 0.2$ to $1.1 \mathrm{~m} / \mathrm{s}$, and 105 to $406 \mathrm{~Pa}$, respectively (Table 5).

\subsection{Sediment Mobilization and Preservation of Patches}

[26] Despite modest discharges during the study period, eight of the nine painted patches experienced grain mobilization annually. Field visits before and after storm events showed that sediment movement occurred during large discharge events in the middle to the end of the rainy season when stage heights were high. Intensive monitoring in winter 2008/2009 showed that transport from the patch in reach 1 was limited to a single storm event, two storm events produced sediment transport from the patch in reach 4, three storm events produced transport from patches in reach 2 , and reach 3 experienced transport from patches in multiple events (reach 5 was not visited during storms due to inaccessibility).

[27] Repeat pebble counts of painted patches show that patch median grain size $\left(D_{50}\right)$ remained fairly constant (generally within a factor of 3 ) over the study period for all cases (Figure 8). However, when coarsening or fining did occur, these trends were often reflected in multiple patches across a reach suggesting a reach-wide change in grain size.

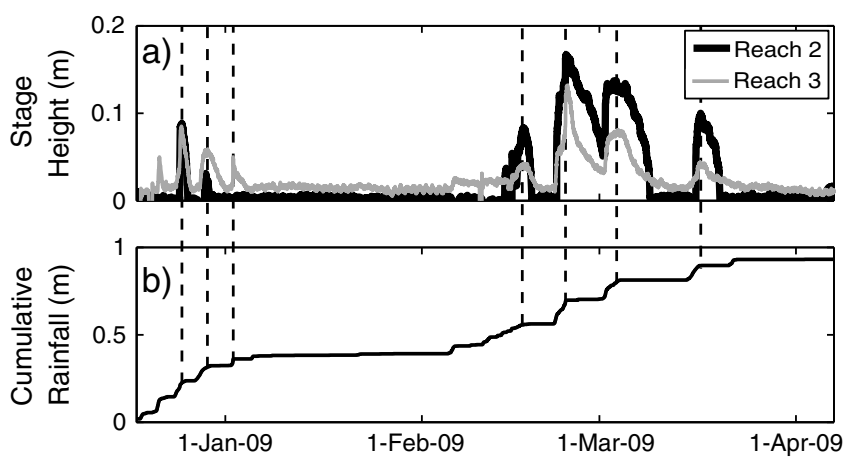

Figure 6. (a) Hydrographs of water stage height for reaches 2 and 3 during winter 2008/2009. (b) Cumulative rainfall for the same time period as in Figure $6 \mathrm{a}$ from a weather station $<2 \mathrm{~km}$ from the Elder Creek watershed. Dashed vertical lines are for reference. 


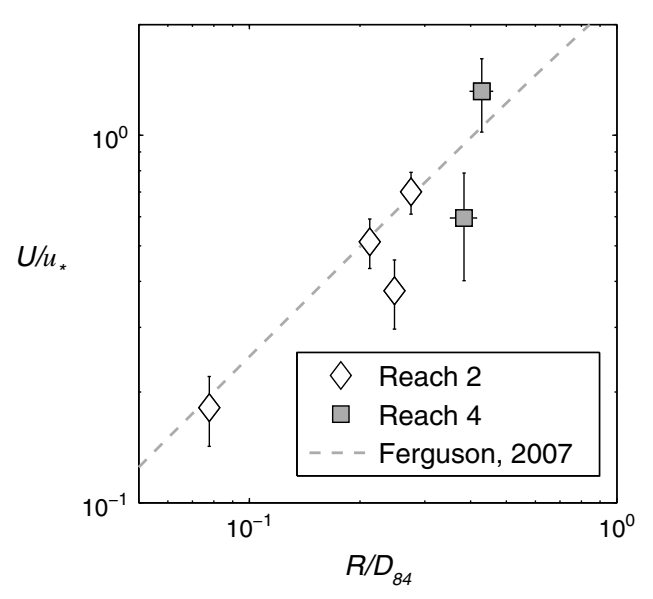

Figure 7. Comparison of the HEC-RAS iterated values of $U / u_{*}$ to those predicted by Ferguson [2007] (equation (2)) as a function of $R / D_{84} . U, u_{*}$, and $R$ are the reach-averaged flow velocity, shear velocity, and hydraulic radius, respectively, as predicted by HEC-RAS. $D_{84}$ is the grain size for which $84 \%$ of the bed is finer (i.e., the reach-averaged $D_{84}$ ). Horizontal and vertical error bars show standard error of the mean, error is smaller than the symbol where no error bars are shown.

[28] Despite mobilization of gravel in patches, a large fraction of the bed was observed to be stationary over the study period both within painted patches and in the reaches as a whole. For patches with regular grain mobilization, the largest grains available in a patch were rarely moved (Figure 9), thus providing evidence that the patches experienced partial transport. For example, $75 \%$ of transport events from individual patches failed to move grains larger than half the diameter of the maximum grain size present within the patch (Figure 9). Of the 50 individually painted cobbles and boulders, only six cobbles moved. These were generally among the smaller grains $(D<150 \mathrm{~mm})$ and were not interlocked. Transport distances for these painted cobbles and boulders were short $(0.2-1 \mathrm{~m})$. The lack of movement of large cobbles and boulders suggests that the tributaries underwent reach-wide partial transport of sediment. Reach-wide partial transport was additionally documented in reach 2 where a small dam designed to trap sediment deployed in the 2008/2009 winter collected $4.3 \mathrm{~kg}$ of sediment and showed that the maximum grain size that moved through the reach $(70 \mathrm{~mm})$ was less than the reach-averaged median grain size $(97 \mathrm{~mm})$.

\subsection{Particle Travel Distance}

[29] Particle travel distance is a function of both grain weight and the grain size relative to the bed (as smaller particles are more likely to become trapped behind larger particles [e.g., Einstein, 1950]). In a compilation of worldwide streams, Church and Hassan [1992] found an inverse relationship between particle size and distance traveled, and other more recent studies [e.g., Wilcock, 1997; Ferguson and Wathen, 1998; Lenzi, 2004; Hodge et al., 2011] have found similar trends. An inverse trend between particle size and distance transported is expected if grain weight is the dominant control on particle travel distance; however, preferential trapping of smaller particles within a bed composed of larger grains can cause deviations from this trend [e.g., Kirchner et al., 1990]. Church and Hassan [1992] noted that distance transported may depend strongly on grain weight for particles with $D / D_{50}>\sim 2$, whereas particles with $D / D_{50}<\sim 2$ have a higher likelihood of being trapped within the bed of coarser grains, and therefore their distance traveled may depend less on grain weight.

[30] Data on transport distance for all recovered grains (i.e., all patches with mobile sediment) in this study show a slight inverse relationship between travel distance and grain size and general agreement with the shape of the Church and Hassan [1992] relationship but a systematic offset to lower values of the normalized travel distance (Figure 10). Data in Figure 10 suggest that smaller particles were transported slightly farther than larger particles in our studied reaches. Note that Church and Hassan [1992] normalized grain size by $D_{50}$ of the bed subsurface and that we normalize by $D_{50}$

Table 5. Reach-Averaged Flow Hydraulic Data for Specific Sediment-Transport Events ${ }^{\mathrm{a}}$

\begin{tabular}{|c|c|c|c|c|c|c|c|c|}
\hline Reach & Storm & $\tau_{T}(\mathrm{~Pa})$ & $U(\mathrm{~m} / \mathrm{s})$ & $R(\mathrm{~m})$ & $R / D_{84 \text {-mobile }}$ & $\tau_{f d} / \tau_{T}$ Power Law $C_{m}$ & $\tau_{f d} / \tau_{T}$ Mean $C_{m}$ & $\tau_{f d} / \tau_{T} \operatorname{VPE} C_{m}$ \\
\hline 1 & Winter $2007 / 2008$ & 199 & 0.50 & 0.08 & 1.78 & 0.77 & 0.72 & 0.89 \\
\hline 1 & 24 Feb 2009 & 239 & 0.30 & 0.05 & 1.00 & 0.89 & 0.92 & 0.92 \\
\hline 1 & Winter $2009 / 2010$ & 222 & 0.34 & 0.05 & 1.21 & 0.86 & 0.89 & 0.91 \\
\hline 2 & Winter $2007 / 2008$ & 256 & 0.48 & 0.12 & 0.82 & 0.68 & 0.80 & 0.75 \\
\hline 2 & 25 Dec 2008 & 150 & 0.20 & 0.06 & 0.44 & 0.83 & 0.94 & 0.87 \\
\hline 2 & 24 Feb 2009 & 216 & 0.37 & 0.10 & 0.67 & 0.75 & 0.87 & 0.76 \\
\hline 2 & Winter $2009 / 2010$ & 233 & 0.42 & 0.11 & 0.73 & 0.74 & 0.85 & 0.77 \\
\hline 3 & Winter $2007 / 2008$ & 185 & 0.86 & 0.32 & 2.24 & 0.37 & 0.12 & 0.73 \\
\hline 3 & 14 Nov 2008 & 231 & 0.22 & 0.09 & 0.59 & 0.90 & 0.95 & 0.90 \\
\hline 3 & 25 Dec 2008 & 202 & 0.28 & 0.11 & 0.78 & 0.85 & 0.91 & 0.87 \\
\hline 3 & 24 Feb 2009 & 172 & 0.33 & 0.14 & 0.95 & 0.79 & 0.86 & 0.85 \\
\hline 3 & Winter $2009 / 2010$ & 164 & 0.51 & 0.20 & 1.39 & 0.63 & 0.65 & 0.79 \\
\hline 4 & Winter $2007 / 2008$ & 388 & 0.72 & 0.26 & 1.33 & 0.70 & 0.71 & 0.84 \\
\hline 4 & 24 Feb 2009 & 406 & 0.53 & 0.20 & 1.01 & 0.79 & 0.85 & 0.85 \\
\hline 4 & Winter $2009 / 2010$ & 388 & 0.75 & 0.27 & 1.37 & 0.68 & 0.68 & 0.83 \\
\hline 5 & Winter $2007 / 2008$ & 107 & 1.05 & 0.34 & 3.83 & 0.14 & -1.27 & 0.71 \\
\hline 5 & 24 Feb 2009 & 108 & 0.48 & 0.20 & 2.22 & 0.71 & 0.53 & 0.89 \\
\hline 5 & Winter $2009 / 2010$ & 105 & 0.91 & 0.30 & 3.35 & 0.25 & -0.74 & 0.74 \\
\hline
\end{tabular}

${ }^{\mathrm{a}} \tau_{T}, U$, and $R$ are reach-averaged bed shear stress, flow velocity, and hydraulic radius calculated with HEC-RAS. $D_{84-m o b i l e}$ is the 84 th percentile reachaveraged mobile grain size, and $\tau_{f d} / \tau_{T}$ is fractional form drag for the power law, mean, and VPE $C_{m}$ methods (section 5.1). Listing of individual storm dates (e.g., 24 Feb 2009) indicates measurements were made for a specific storm event. Listing of a season (e.g., Winter 2007/2008) indicates measurements integrate multiple storm events over an entire season, with the peak observed discharge event assumed to have transported all the sediment. 

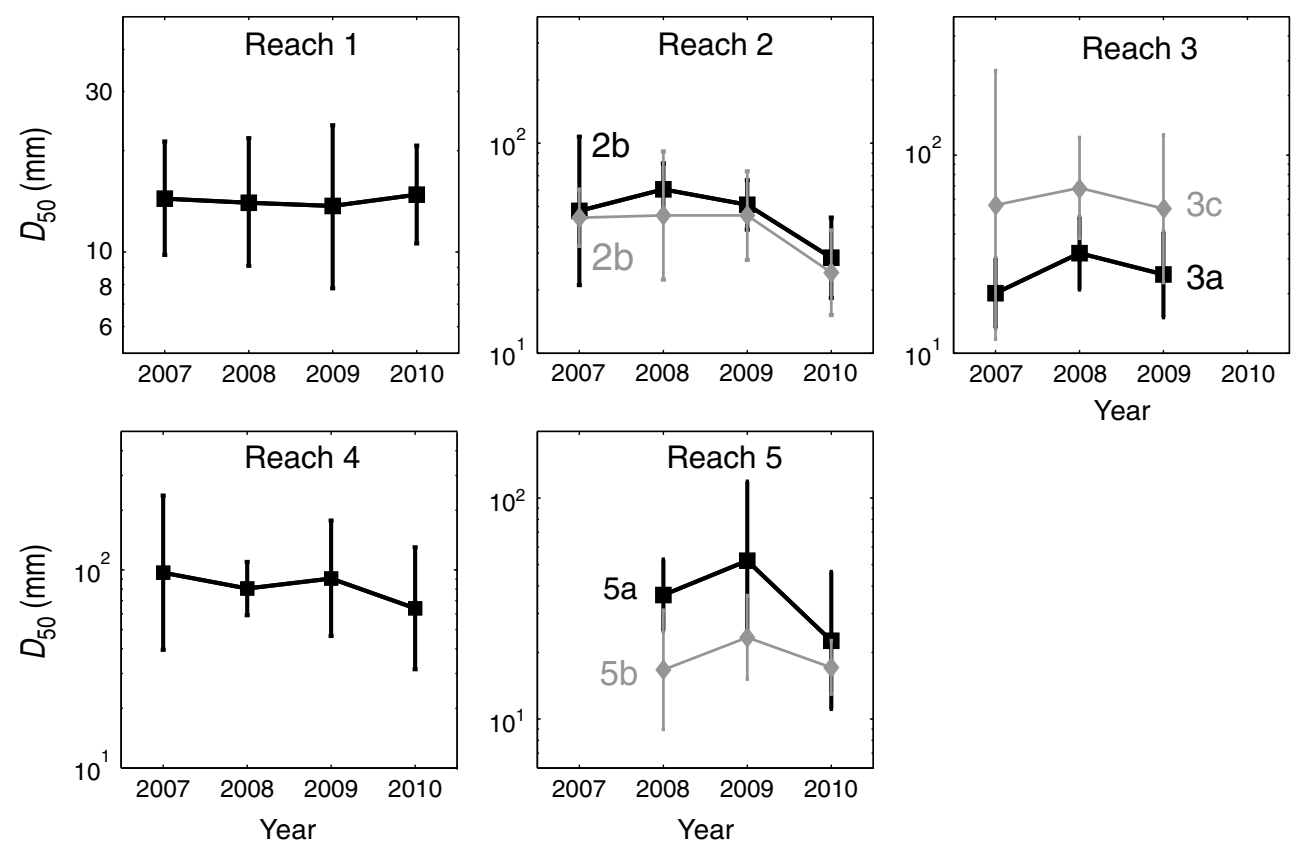

Figure 8. Median grain size $\left(D_{50}\right)$ and $95 \%$ confidence intervals [Bunte and Abt, 2001] for individual patches examined in this study. Each plot represents a different studied reach, and each line series within a plot is a unique patch for the given reach (noted by patch label where appropriate, i.e., " $2 b$ " is patch $2 b$ from Table 4).

of the bed surface. This difference in normalization may explain the systematic offset between the data presented here and the Church and Hassan [1992] relationship because the surface of the reaches examined in this study were in most cases armored. Despite increased probability of trapping small grains for $D / D_{50}<2$, we still observed an overall inverse relationship between grain size and particle transport distance. The increased travel distance of small particles allows for replacement of gravel within patches by similar sized grains which may be sourced from distances several meters upstream.

\section{Analysis}

[31] In this section, we present an analysis of our sediment-transport data in order to estimate critical Shields stress for incipient motion and compare our calculated Shields stress values to theoretical models. We then use flow hydraulic data to estimate form drag and attempt to quantify individually the effects of form drag, slopedependent hydraulics, bed patchiness, and grain hiding on critical Shields stress.

\subsection{Critical Shields Stress}

[32] Determining the exact timing of incipient motion for a given particle is difficult. Since no universal metric is used to define the onset of incipient motion [Buffington and Montgomery, 1997], we calculated critical Shields stresses using two different approaches to avoid biases associated with a single technique. First, we used a flow competence approach and assumed the largest transported grain moved at the peak observed bed shear stress $\left(\tau_{\max }\right)$ [Andrews, 1983]. With this assumption, equation (1) can be rewritten as

$$
\tau_{* c}=\frac{\tau_{\max }}{\left(\rho_{s}-\rho\right) g D_{\max }}
$$

where $D_{\max }$ is the largest grain observed to move from a given patch for a given storm event (or integration of multiple storms). This approach is frequently used in field studies of motion in streams with moderate to steep slopes [e.g., Church and Hassan, 2002; Lenzi et al., 2006; Mao et al., 2008; Thompson and Croke, 2008].

[33] Second, we estimated $\tau_{*_{c}}$ by assuming that all transported grains deposited within $1 \mathrm{~m}$ of the patch from which they originated were at incipient motion during the flood peak. For this method, we calculated the critical Shields stress as

$$
\tau_{* c}=\frac{\tau_{\max }}{\left(\rho_{s}-\rho\right) g D_{1 \text { meter }}}
$$

where $D_{1 \text { meter }}$ is the mass weighted geometric mean grain diameter of all particles (always $>5$ grains) recovered within $1 \mathrm{~m}$ downstream of the patch from which they originated. We refer to the second approach as the "one-meter method." The one-meter method is similar to the particle displacement approach which is often used in steep streams [e.g., Lenzi et al., 2006; Mao et al., 2008]; however, we were unable to measure subgrain-diameter movement (as required for the particle displacement approach) since grains must move out of the painted patch in order to observe definitive movement. Note that even though we had low recovery rates of grains transported from patches, estimates of $D_{\max }$ and $D_{1 \text { meter }}$ are likely accurate as large grains (i.e., $D_{\max }$ ) are easier to see, less likely to be buried, and travel shorter distances than fine grains (Figure 10). Recovery rates of grains deposited near the patch (i.e., $D_{1 \text { meter }}$ ) should be high as these grains come 


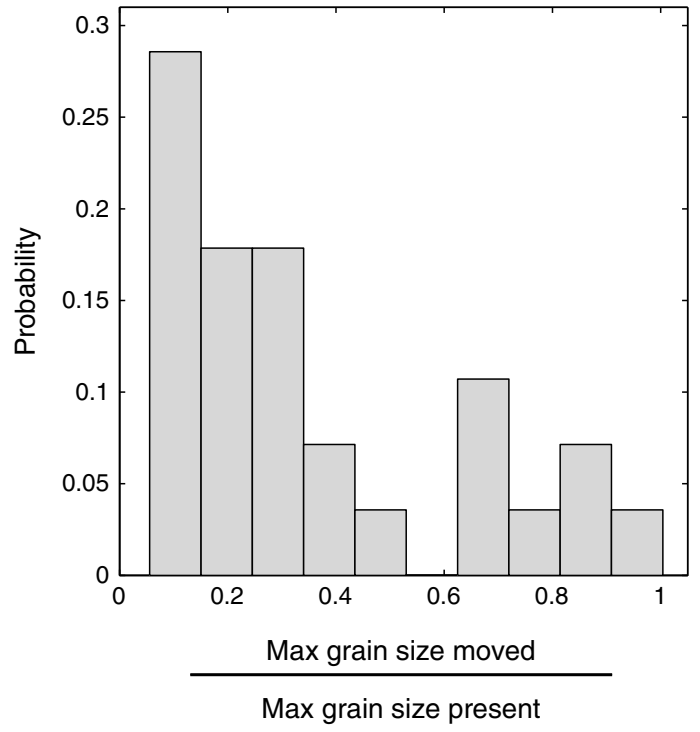

Figure 9. Probability distribution of the maximum grain size moved from a patch for a given storm event relative to the maximum grain size available in the patch for movement. These data integrate all observed transport events for each individual patch over the 3 year study period.

from a small area which was thoroughly searched. For both the flow competence and one-meter methods, we estimated $\tau_{\max }$ locally using the modeled bed shear stress given by HECRAS (section 3.3, Table 4), which reflects shear stress spent on both mobile and immobile elements (i.e., the total shear stress).

[34] Neither of the above approaches provides a perfect measure of the conditions for incipient motion. The flow competence approach assumes that the largest grain recovered was mobilized at the highest calculated bed shear stress (and therefore that smaller grains are mobilized at lower shear stresses than larger grains, a condition that generally exists for gravel-bed streams [Parker, 2008]) and is only valid for cases where the largest grains in the patch remain stationary (i.e., partial transport of the patch, which was met in this study). Wilcock [1992] notes that flow competence estimates are subject to large errors as they are based on an extreme value of the transport grain-size distribution. Similarly, since the flow competence approach uses only a single grain to estimate critical Shields stress, the conditions for mobilization may largely be a function of local pocket geometry, protrusion, interaction with surrounding grains (e.g., locked in place or free to move), and other local conditions at the grain scale [e.g., Kirchner et al., 1990].

[35] The one-meter method uses the geometric mean grain diameter of all particles recovered, thus averaging over grain-scale heterogeneity inherent with the flow competence method. However, the one-meter approach assumes that grains at incipient motion are transported shorter distances than grains at high transport stages [e.g., Wiberg and Smith, 1985]. While this is consistent with our data in general (Figure 10), in some cases, the stopping location of a grain may be a function of the transported grain size relative to the local roughness on the bed [e.g., Dietrich et al., 2006] or a function of the transported grain size itself [e.g., Church and Hassan, 1992], which may introduce error in this method.
[36] Our inferred critical Shields stress values for particles that moved are similar for both the flow competence and one-meter methods and vary over 2 orders of magnitude from $\sim 0.02$ to 2 . The majority of $\tau_{*_{c}}$ estimates have values greater than what is typically assumed for gravel-bedded rivers (i.e., $\tau_{*_{c}}=0.045$ ). Large variations in critical Shields stresses may result from slope-dependent hydraulic effects [e.g., Mueller et al., 2005; Lamb et al., 2008a; Recking, 2009], grain hiding, [Einstein, 1950; Egiazaroff, 1965; Wiberg and Smith, 1987], form drag on nonmobile structures [Yager et al., 2007; Yager et al., 2012a], and the presence of sediment patches [Yager et al., 2012b], all of which exist in the steep streams examined here. These are each evaluated in section 5.4 using a force-balance model.

\subsection{Comparison to Critical Shields Stress Models}

[37] We compared our field-estimated critical Shields stresses to the theoretical relationships proposed by Wiberg and Smith [1987] and Lamb et al. [2008a] (which gives similar results to Recking [2009]), as well as the empirical relationships proposed by Mueller et al. [2005] and Ferguson [2012]. Wiberg and Smith [1987] proposed a force-balance model which predicts grain motion for coarse grains primarily as a function of the grain size relative to the local roughness (i.e., $D / k_{s}$, where $D$ is the grain size of interest, and $k_{s}$ is the local channel roughness for large particle Reynolds numbers). This model predicts that $\tau_{*_{c}}$ decreases with increasing slope due to the additional component of gravity in the downstream direction. Lamb et al. [2008a] modified the Wiberg and Smith [1987] model to include slope-dependent hydraulic effects and fractional form drag, resulting in a prediction of increasing $\tau_{*_{c}}$ with slope. For this section, we set fractional form drag to zero in the Lamb et al. [2008a] model (the influence of form drag is examined in section 5.4). Mueller et al. [2005] predict a positive linear relationship between $\tau_{*_{c}}$ (for the median particle size) and slope based on a fit to field data for slopes up to $S=0.05$.

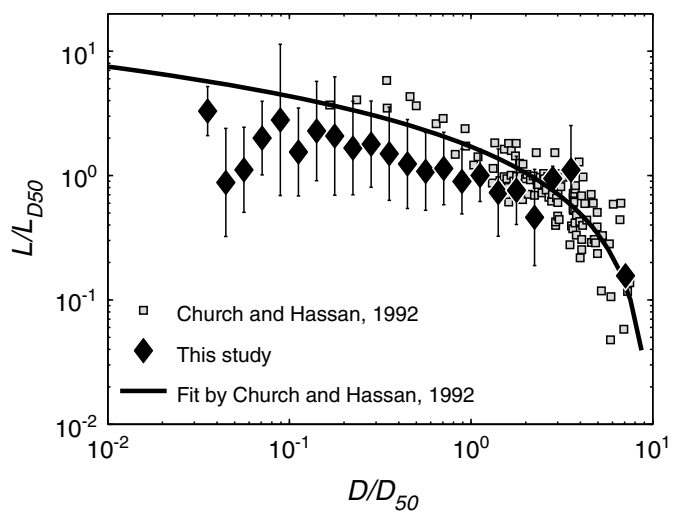

Figure 10. Binned relative grain size moved versus relative distance traveled for tracer pebbles in this study (black diamonds) and other studies (gray squares). Error bars are 1 geometric standard deviation of binned data. Solid black line is prediction from Church and Hassan [1992]. L is the travel distance of a single particle, $L_{D 50}$ is the expected travel distance of the median grain size based on a power law fit to the data, $D$ is the grain size of the moved particle, and $D_{50}$ is median grain size of the surface (this study) or subsurface [Church and Hassan, 1992]. 

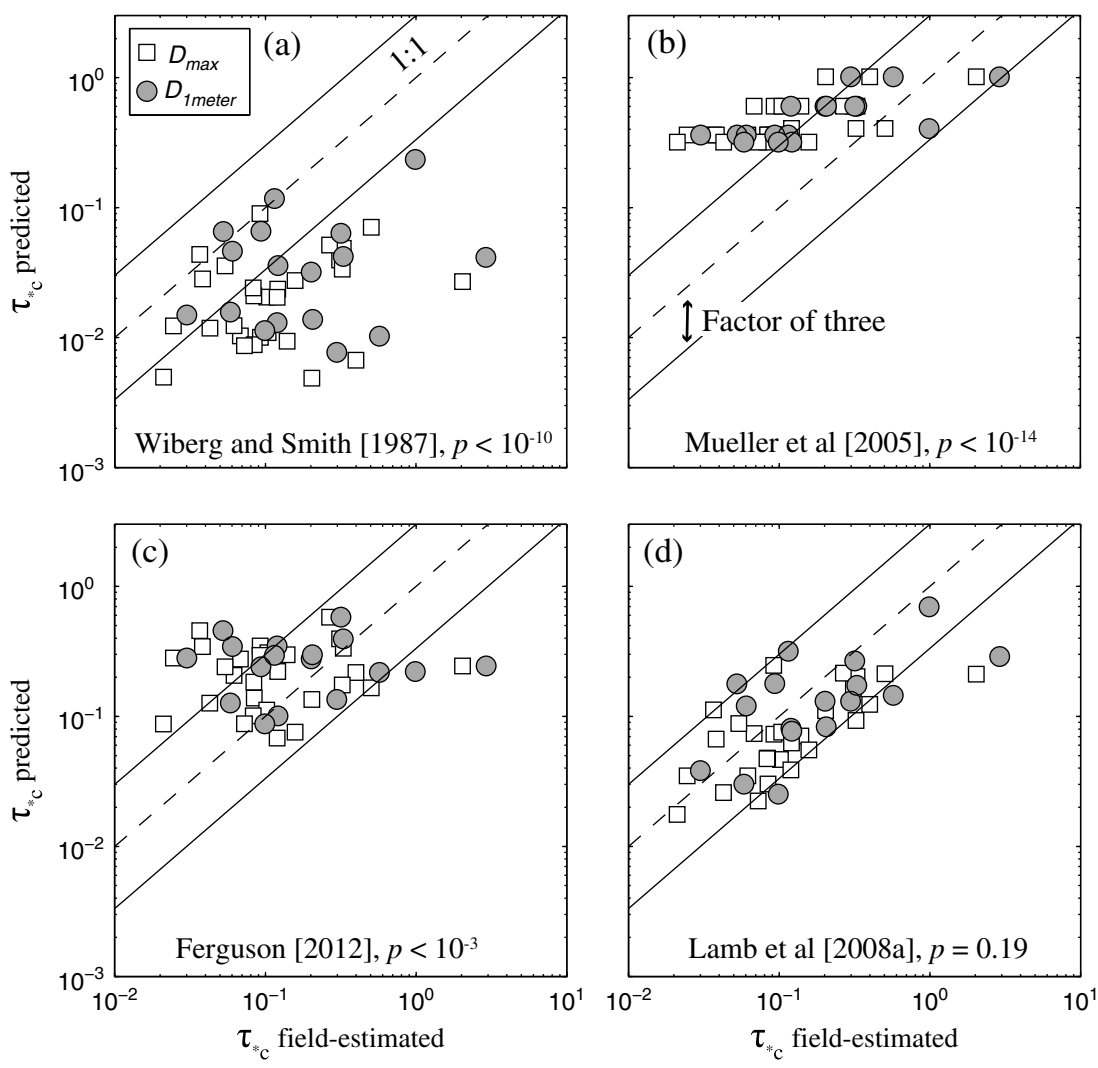

Figure 11. Comparison of theoretical and empirical predictions to field-estimated critical Shields stresses $\left(\tau *_{c}\right)$. Theories examined include (a) Wiberg and Smith [1987], (b) Mueller et al. [2005], (c) Ferguson [2012], and (d) Lamb et al. [2008a]. In all plots, dashed line is 1:1 line, and solid lines show factor of 3 deviation from 1:1 line. Open squares and gray circles are Shields stresses calculated using the flow competence $\left(D_{\max }\right)$ and one-meter $\left(D_{1 \text { meter }}\right)$ methods, respectively. For Ferguson [2012] predictions, all constants were set to recommended values in Ferguson [2012], $D_{84}$ was set to $D_{84 \text {-mobile, }} D_{50}$ was set to the $D_{50}$ of the local patch in question, and the HEC-RAS calculated reach-averaged hydraulic radius was used in place of flow depth. For both the Wiberg and Smith [1987] and Lamb et al. [2008a] predictions, fractional form drag was set equal to zero. Results of the two-sample Kolmogorov-Smirnov test comparing field-estimated versus model-predicted Shields stress distributions are displayed for each plot, $p<0.05$ indicates distributions are statistically different at the 5\% significance level.

Ferguson [2012] attributes the heightened $\tau_{*_{c}}$ with increasing slope entirely to form drag.

[38] We evaluated the ability of each model to predict our field data by performing a two-sample Kolmogorov-Smirnov test of the log-transformed field-estimated and modelpredicted critical Shields stress data. The KolmogorovSmirnov test assesses the null hypothesis that two populations of values belong to the same distribution. In our case, rejection of the null hypothesis indicates a statistical difference between the field-estimated versus model-predicted critical Shields stress distributions, which we interpret to mean the model in question does a poor job of predicting critical Shields stress. The Kolmogorov-Smirnov test is advantageous to other goodness of fit measures (e.g., $r^{2}$ or residual sum of squares) as it examines the full cumulative distribution function and is thus less sensitive to a single outlier, and it is designed for small sample sizes [Zar, 1999].

[39] The models described above differ widely in their ability to match our calculated critical Shields stresses (Figure 11). The Wiberg and Smith [1987] model tends to underpredict critical Shields stresses, which is likely a result of the steep slopes examined here for which the model predicts decreased Shields stress due to the increased component of gravity in the downstream direction (Figure 11a). Both the Mueller et al. [2005] and Ferguson [2012] models predict critical Shields stress for the median grain size only and thus do not match well our data of grains both smaller and larger than the median size (Figures $11 \mathrm{~b}$ and 11c). The distribution of critical Shields stresses predicted by the Wiberg and Smith [1987], Mueller et al. [2005], and Ferguson [2012] models are statistically different from the distribution of our field-estimated values by the Kolmogorov-Smirnov test (for all three models $p<0.001$ ).

[40] The Lamb et al. [2008a] relationship is the only model for which we cannot reject the null hypothesis of the Kolmogorov-Smirnov test, and the predicted critical Shields stresses are generally within a factor of 3 of the field data (Figure 11d). The factor of 3 in scatter is observed in other studies as well, including controlled flume experiments, and can arise from the stochastic nature of turbulent flow and sediment transport alone [e.g., Mizuyama, 1977; Kirchner et al., 1990; Buffington and Montgomery, 1997]. The data 


\section{SCHEINGROSS ET AL.: GRAVEL MOBILIZATION IN STEEP CHANNELS}

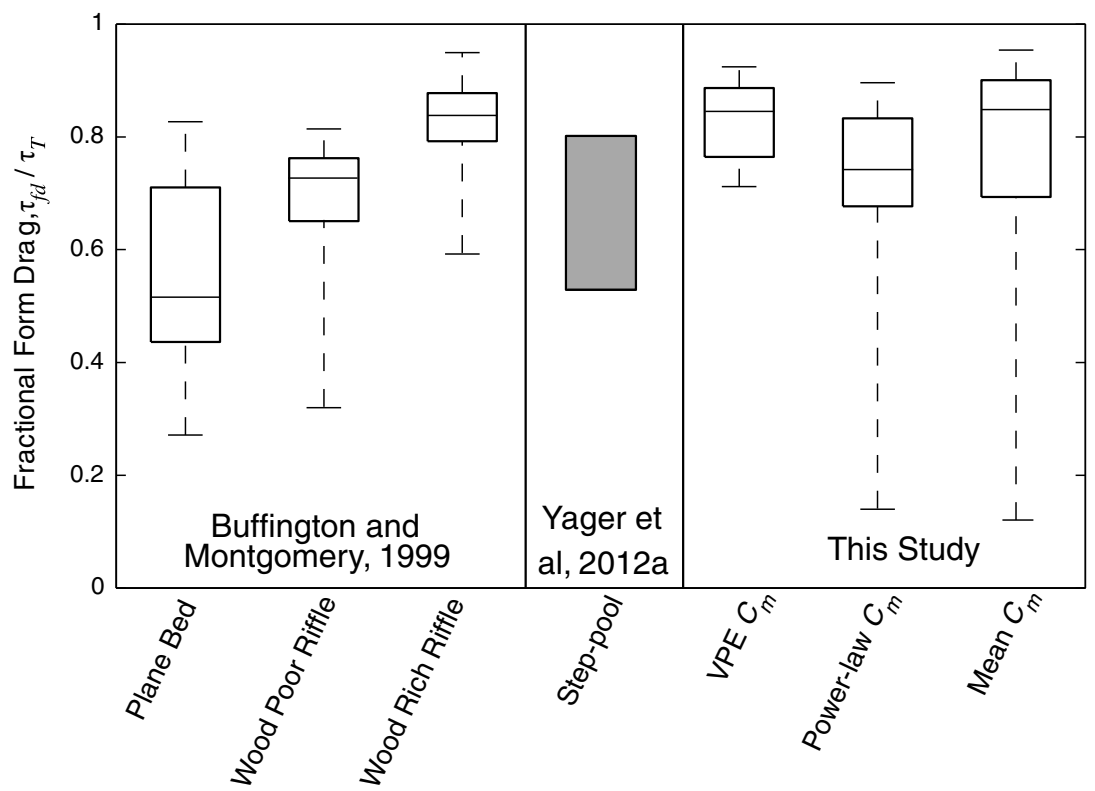

Figure 12. Box and whisker plots of fractional form drag $\left(\tau_{f d} / \tau_{T}\right)$ from different morphology channels in Buffington and Montgomery [1999] and from this study; solid gray box shows range of form drag calculated from Yager et al. [2012a]. For this study, we report fractional form drag ranges using the VPE, power law, and mean $C_{m}$ methods (see text for details). Boxes bound the data between the 25 th to 75 th percentile values, the line within the box is the data median, and whiskers show data extent.

consistency with the Lamb et al. [2008a] model suggests that slope-dependent hydraulic effects, local channel roughness, and grain hiding affect incipient sediment motion.

\subsection{Form Drag}

[41] In steep streams, the presence of large immobile grains and particle clusters leads to a reduced portion of the total shear stress available to act on the mobile sediment [e.g., Brayshaw et al., 1983; Wiberg and Smith, 1991; Buffington and Montgomery, 1999; Millar, 1999; Yager et al., 2007; Yager et al., 2012a]. We accounted for this reduced shear stress on mobile grains by calculating a "fractional form drag," $\tau_{f d} / \tau_{T}$, where $\tau_{f d}$ is the bed shear stress spent on immobile morphologic structures and $\tau_{T}$ is the total bed shear stress. We calculated fractional form drag following Yager et al. [2012a] as

$$
\frac{\tau_{f d}}{\tau_{T}}=1-\frac{\tau_{m}}{\tau_{T}}=1-\frac{0.5 \rho C_{m} U^{2}}{\tau_{T}}
$$

where $\tau_{m}$ is the shear stress on the mobile grains and $C_{m}$ is the drag coefficient for mobile sediment. We used results from the HEC-RAS modeling to solve for the reachaveraged $\tau_{T}$ (section 3.3 and Table 5). Drag coefficients for mobile sediment are not well known; thus, we estimated $C_{m}$ with three different methods to check for consistency.

[42] The first two methods use hydraulic data reported by Marcus et al. [1992] for a steep mountain stream. Following Yager et al. [2012a], we assumed $\tau_{T}=\tau_{m}$ in the data of Marcus et al. [1992] based on the observation of minimal boulders, steps, and other structures, and calculated $C_{m}$ from 15 separate flow measurements using a normal-flow approximation for $\tau_{T}$ so that

$$
C_{m}=\frac{2 \tau_{T}}{\rho U^{2}}=2\left(\frac{u_{*}}{U}\right)^{2}=\frac{2 g R S}{U^{2}}
$$

[43] Note that the channel studied by Marcus et al. [1992] likely has some form drag on immobile structures, and our estimates of $C_{m}$ from this data should be considered maximum values. These $C_{m}$ estimates vary as a function of $R / D_{84}$, although the data are scattered. This scatter caused Yager et al. [2012a] to adopt a constant value of $C_{m}$,

$$
C_{m}=0.44
$$

[44] Which is an average of the mobile drag coefficients calculated from the Marcus et al. [1992] data. We used both the mean $C_{m}$ value and also fit a power law to the data (hereafter referred to as the "power law $C_{m}$ " method),

$$
C_{m}=0.57\left(R / D_{84-\text { mobile }}\right)^{-0.96}
$$

with $r^{2}=0.42$ and where $D_{84-m o b i l e}$ is the reach-averaged grain size for which $84 \%$ of mobile sediment is finer. Equation (8) allowed calculations of a flow-depth dependent mobile drag coefficient for sediment-transport events in this study, where reach-averaged $R$ was obtained from

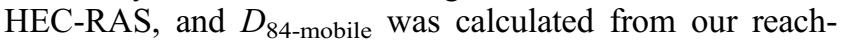
averaged pebble counts ignoring all grains larger than the maximum observed mobile particle for a given reach (based on painted particle tracer data) (Table 1).

[45] In addition to the two techniques described above, we also calculated $C_{m}$ using the variable power equation (VPE) of Ferguson [2007] (hereafter referred to as the "VPE $C_{m}$ " method) following methods similar to those proposed by Rickenmann and Recking [2011] for flow resistance partitioning. We set $D_{84 \text {-mobile }}$ as the roughness length scale, 

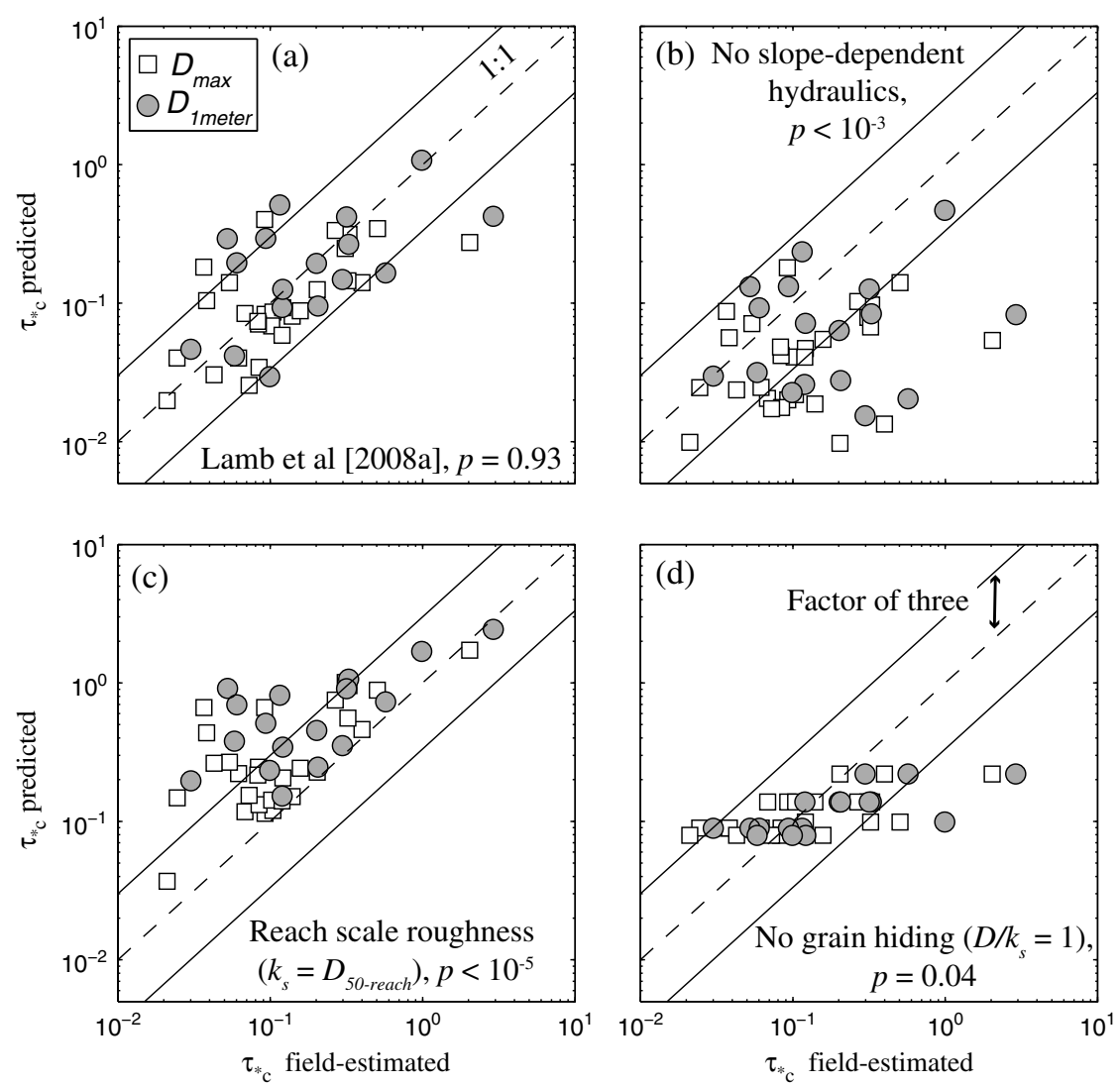

Figure 13. Comparison of model-predicted to field-estimated critical Shields stress $\left(\tau_{*_{c}}\right)$ examining the effects of slope-dependent hydraulics, bed patchiness, and grain hiding. (a) Lamb et al. [2008a] predictions which include the effects of slope-dependent hydraulics, form drag, grain hiding, and patches. (b) Form drag modified Wiberg and Smith [1987] model which includes form drag, patches, and grain hiding effects, but does not include slope-dependent hydraulics. (c) Lamb et al. [2008a] model predictions (where the reach-averaged $D_{50}$ was used as the roughness length scale rather than the patch $D_{50}$ ) which includes form drag, slope-dependent hydraulics, and grain hiding effects, but does not include the effect of bed patchiness. (d) Lamb et al. [2008a] model predictions (with $D / k_{s}=1$ ) which includes form drag, patches, and slope-dependent hydraulics effects, but does not include grain hiding effects. For all predictions, fractional form drag was set to 0.5 ; in Figures $13 \mathrm{a}, 13 \mathrm{~b}$, and $13 \mathrm{~d}$ the patch $D_{50}$ was used as the roughness length scale, $k_{s}$. In all plots, dashed line is 1:1 line, and solid lines show factor of 3 deviation from 1:1 line; open squares and gray circles are Shields stress calculated using the flow competence $\left(D_{\max }\right)$ and one-meter $\left(D_{1 \text { meter }}\right)$ methods, respectively. Results of the two-sample Kolmogorov-Smirnov test comparing field-estimated versus model-predicted Shields stress distributions are displayed for each plot; $p<0.05$ indicates distributions are statistically different at the $5 \%$ significance level.

solved for the Darcy-Weisbach friction factor, $f$, and estimated $C_{m}$ directly by substituting equation (2) into (6). This last method is independent of the Marcus et al. [1992] measurements, is based on a large compilation of flow resistance data, and has been shown to accurately predict flow resistance in steep streams [Rickenmann and Recking, 2011], although its application to form drag rather than flow resistance has not been tested directly.

[46] In our monitored tributaries $\tau_{f d} / \tau_{T}$ ranged from 0.14 to $0.90,0.12$ to 0.95 , and 0.71 to 0.92 with mean values of $0.65,0.74$, and 0.81 for $C_{m}$ estimated with the power law, mean, and VPE methods, respectively (Figure 12 and Table 5). Note that equation (7) (i.e., mean $C_{m}$ ) produced two outliers with $\tau_{f d} / \tau_{T}<0$, which were ignored as negative fractional form drag cannot exist. The results are similar between the three different methods, with all methods predicting large values of form drag and overlapping interquartile ranges (Figure 12).

[47] We compared our calculated fractional form drag in the Elder Creek tributaries to other streams using data from Buffington and Montgomery [1999] and Yager et al. [2012a]. We calculated $\tau_{f d} / \tau_{T}$ from data reported by Buffington and Montgomery [1999] using the difference between the observed median grain sizes and the median grain sizes expected for a channel with no form drag. $\tau_{T}$ was calculated assuming uniform flow (i.e., $\tau_{T}=\rho g h S$, where $h$ is the reach-averaged flow depth and was used in place of hydraulic radius which was not reported), $\tau_{f d}$ was calculated using the observed grain-size distribution on the bed, $\tau_{f d}=\tau_{* c}\left(\rho_{s}-\rho\right) g D_{50}$ (which assumes that the median grain size is set by a representative bed shear stress), and $\tau_{*_{c}}$ was set to 0.03 as suggested by Buffington and 


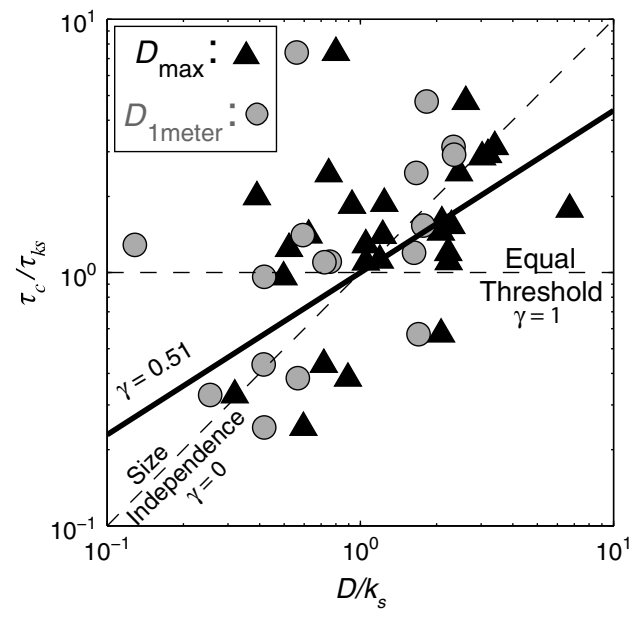

Figure 14. Calculated critical shear stress $\left(\tau_{c}\right)$ normalized by shear stress for $D=D_{50}=k_{s}$ of the patch surface $\left(\tau_{k s}\right)$ versus sediment size $(D)$ normalized by the roughness length $k_{s}$ for both flow competence and $1 \mathrm{~m}$ data. Here $D$ is $D_{\max }$ for flow competence data and $D_{1 \text { meter }}$ for the one-meter method, and $k_{s}$ is the mass weighted geometric mean grain diameter of the surface of the patch from which the grain originated. The solid line is a best fit to all the logtransformed data $\left(\tau_{c} / \tau_{k s}=\left(D / k_{s}\right)^{1-0.51}\right), \mathrm{r}^{2}=0.26$. The $\gamma$ value of 0.51 is statistically distinct from an equal threshold of motion (i.e., $\gamma=1, t$ test, $p=0.002$ ). Also labeled are lines of equal threshold and size independence.

Montgomery [1999]. To calculate fractional form drag from Yager et al. [2012a], we digitized data reporting total shear stress $\left(\tau_{T}\right)$ and shear stress on mobile sediment $\left(\tau_{T}-\tau_{f d}\right)$ (their figure appendix 1d for variable $C_{m}$ ) and calculated a discharge-dependent range of fractional form drag.

[48] The range of $\tau_{f d} / \tau_{T}$ from approximately 0.1 to 0.9 in the Elder Creek tributaries is comparable to (although larger than) the fractional form drag we calculated from the data of Yager et al. [2012a] $\left(0.53<\tau_{f d} / \tau_{T}<0.80\right)$ for a stream of 9.8\% gradient and to data from Buffington and Montgomery [1999] $\left(0.27<\tau_{f d} / \tau_{T}<0.95\right)$ on lower gradient streams with $S=0.2-2.7 \%$ (Figure 12). While the lower limit of the $\tau_{f d} / \tau_{T}$ range is smaller in the Elder Creek tributaries compared to other studies, we note that the 25 th percentile values of $\tau_{f d} / \tau_{T}$ are greater than 0.65 for all three methods, similar to the range of values reported by Yager et al. [2012a]. Larger values of fractional form drag in the Elder Creek tributaries and the Yager et al. [2012a] data may be expected due to the presence of immobile steps and boulders as opposed to the plane bed and pool-riffle sequences analyzed by Buffington and Montgomery [1999]. Our range of calculated form drag is also comparable to that required for the Lamb et al. [2008a] critical Shields stress model to best match their field data compilation $\left(\tau_{f d} / \tau_{T}\right.$ approximately 0.4 to 0.8 , in their Figure 10$)$.

\subsection{Relative Influence of Form Drag, Channel Slope, Patches, and Grain Hiding on Critical Shields Stress}

[49] In this section, we use our field data and the models of Wiberg and Smith [1987] and Lamb et al. [2008a] to investigate the influence of form drag, slope, bed patchiness, and grain hiding on critical Shields stress values. While there exist a number of theoretical and empirical models to predict critical Shields stress (discussed above), we use the Wiberg and Smith [1987] and Lamb et al. [2008a] models because they provide a framework to isolate the effects of form drag, channel slope, grain hiding, and bed patchiness independently.

\subsubsection{Influence of Form Drag}

[50] Our field-estimated critical Shields stresses use HECRAS modeled total bed shear stress and thus include any form drag present within the channel. To assess the form drag influence, we compared field-estimated critical Shields stresses to model predictions which account for form drag by setting $\tau_{f d} / \tau_{T}$ in the Lamb et al. [2008a] model to values calculated using the mean (i.e., equation 7), power law (i.e., equation 8), and VPE $C_{m}$ methods (section 5.3). We also set $\tau_{f d} / \tau_{T}$ to a constant value of $\tau_{f d} / \tau_{T}=0.5$ which best matches the field and flume data collection of Lamb et al. [2008a], as well as $\tau_{f d} / \tau_{T}=0$ for the sake of comparison. For all four form drag parameterizations, as well as the case of no form drag, we cannot reject the null hypothesis of the Kolmogorov-Smirnov test at the $5 \%$ significance level ( $p$ values of $0.07,0.12,0.19$, 0.30 , and 0.93 for the mean $C_{m}$, power law $C_{m}, \tau_{f d} / \tau_{T}=0$, VPE $C_{m}$, and $\tau_{f d} / \tau_{T}=0.5$ form drag parameterizations, respectively). This result implies that it may be possible to explain the field-estimated critical Shields stress values with or without the inclusion of form drag, and thus, the influence of form drag

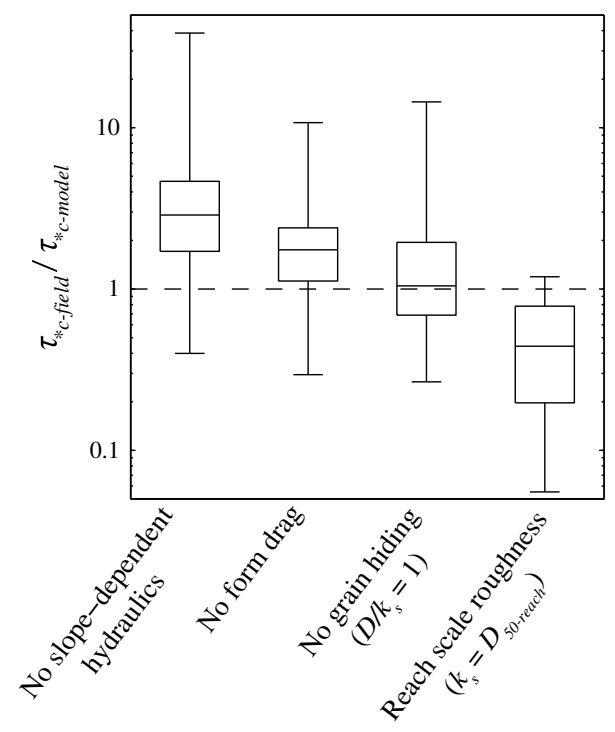

Figure 15. Box and whisker plots of the ratio of fieldestimated $\left(\tau_{*_{c} \text {-field }}\right)$ to model-predicted $\left(\tau_{*_{c-\text {-model }}}\right)$ critical Shields stress $\left(\tau_{*_{c}}\right)$. Boxes bound the data between the 25 th to 75th percentile values, the line within the box is the data median, and whiskers show data extent. Dashed line at $\tau_{*_{c-\text { field }}} / \tau_{*_{c-\text { model }}}=1$ separates effects which increase $\left(\tau_{*_{c} \text {-field }} / \tau_{*_{c \text {-model }}}>1\right)$ and decrease $\left(\tau_{*_{c} \text {-field }} / \tau_{*_{c} \text {-model }}<1\right)$ critical Shields stress. For all model predictions, fractional form drag was set to 0.5 , and the patch median grain size was used as the roughness length scale, unless otherwise specified. Model predictions used include the Wiberg and Smith [1987] theory ("no slope-dependent hydraulics"), Lamb et al. [2008a] theory with fractional form drag set to zero ("no form drag"), Lamb et al. [2008a] theory with $D / k_{s}=1$ ("no grain hiding"), and Lamb et al. [2008a] theory where the reach-averaged $D_{50}$ was used as the roughness length scale rather than the patch $D_{50}$ ("reach scale roughness"). 
may be small compared to other factors which influence critical Shields stress (i.e., grain hiding, bed patchiness, and slopedependent hydraulics discussed below). Setting fractional form drag to a constant value of $\tau_{f d} / \tau_{T}=0.5$ visually appears to match the field data well (Figure 13a), and we use this value for the remainder of model calculations; however, using other form drag parameterizations does not change the main points of this paper.

\subsubsection{Influence of Hydraulics at Steep Slopes}

[51] Changes in the flow velocity structure, turbulent fluctuations, and grain emergence at low flow depth to bedroughness ratios lead to increased $\tau_{*_{c}}$ for steep slopes [Lamb et al., 2008a; Recking, 2009]. To isolate these slope-dependent effects on critical Shields stress, we compared our results to model predictions of Wiberg and Smith [1987] which does not include these effects. Following the methodology of Lamb et al. [2008a], we added a fractional form drag term $\left(\tau_{f d} / \tau_{T}=0.5\right)$ to the Wiberg and Smith [1987] model so that differences between the Lamb et al. [2008a] and Wiberg and Smith [1987] models reflect only the inclusion of slopedependent flow hydraulics and grain emergence in the former. The Wiberg and Smith [1987] model tends to underpredict the field-estimated critical Shields stress values and is statistically distinct from the distribution of field data $(p=0.0002$ in a two-sample Kolmogorov-Smirnov test, Figure 13b). This implies that incipient sediment motion is influenced by slope-dependent hydraulics.

\subsubsection{Influence of Patches and Local Roughness}

[52] The agreement between calculated and modeled critical Shields stresses in Figure 13a was achieved in part because of the field identification of individual, size-sorted sediment patches used to define the local roughness scale of the bed (i.e., $k_{s}$ ). Because steep streams include both relatively mobile fine gravel and less mobile cobbles and boulders [e.g., Yager et al., 2012a;b], using reach-averaged median grain size $\left(D_{50 \text {-reach }}\right)$ as the roughness length scale (i.e., $\left.k_{s}=D_{50 \text {-reach }}\right)$ as opposed to local median grain size of the patch $\left(D_{50 \text {-patch }}\right)$ as the roughness length scale (i.e., $k_{s}=D_{50 \text {-patch }}$ ) can lead to predictions of no sediment motion due to artificially inflated critical Shields stresses. To illustrate this point, we compared Lamb et al. [2008a] model predictions of critical Shields stresses to our data using patch- versus reach-averaged median grain size as the bed-roughness length scale, with $\tau_{f d} / \tau_{T}=0.5$. Setting $k_{s}=D_{50 \text {-reach }}$ tends to over-predict critical Shields stress and results in statistically distinct distributions of field and model data $\left(p<10^{-5}\right.$, two-sample KolmogorovSmirnov test, Figure $13 \mathrm{c}$ ), while using $k_{s}=D_{50 \text {-patch }}$ does not ( $p=0.93$, two-sample Kolmogorov-Smirnov test, Figure 13a). These results imply that initial sediment motion in steep channels is influenced by local roughness controlled by bed surface patchiness.

\subsubsection{Influence of Grain Hiding}

[53] We compared our calculated $\tau_{*_{c}}$ values to those predicted by the Lamb et al. [2008a] model with $D / k_{s}=1$ (i.e., ignoring grain hiding) versus $D / k_{s}$ set equal to the value measured in the field. For both cases, we set $\tau_{f d} / \tau_{T}=0.5$ and used a two-sample Kolmogorov-Smirnov test to evaluate model performance. A model without grain hiding can lead to both overprediction and underprediction of $\tau_{*_{c}}$ depending on if $D / k_{s}$ is less than or greater than unity, respectively. This effect is illustrated in Figure 13d, where model predictions with $D / k_{s}=1$ are approximately evenly distributed above and below the 1:1 line. The distribution of critical Shields stresses predicted with $D / k_{S}=1$ are statistically distinct at the 5\% significance level from the field-estimated Shields stresses (where $D / k_{s}$ is allowed to vary, $p=0.037$ ), implying that including grain hiding within patches influences initial motion in our dataset.

[54] We also examined the influence of relative grain size using a hiding function [e.g., Parker, 2008],

$$
\frac{\tau_{c}}{\tau_{k s}}=\left(\frac{D}{k_{s}}\right)^{1-\gamma}
$$

where $\tau_{c}$ is the critical shear stress for the grain size of interest, $\tau_{k s}$ is the critical shear stress for $D=k_{s}$, and $\gamma$ is a nondimensional constant that describes the relative importance of hiding effects on grain mobilization. Following the terminology of Parker [2008], we refer to the case when $\gamma=0$ as "size independence" (the critical shear stress to mobilize grains is linearly proportional to grain diameter; hence, there are no hiding effects) and when $\gamma=1$ as "equal threshold" (hiding effects dominate causing all grains to move at the same critical shear stress).

[55] We estimated $\gamma$ using our field data to find a best fit to equation (9). We used HEC-RAS modeling to estimate $\tau_{c}\left(\tau_{\max }\right.$ in Table 4$)$ and calculated $\tau_{k s}$ using the Lamb et al. [2008a] model (with $\tau_{f d} / \tau_{T}=0.5$ ). We found $\gamma=0.51$ based on a linear best fit to our log-transformed incipient-motion data (Figure 14). The data are scattered $\left(\mathrm{r}^{2}=0.26\right)$, but our $\gamma$ value of 0.51 is statistically distinct from equal threshold of motion (i.e., $\gamma=1)$ based on a $t$ test $(p=0.002)$. The best-fit $\gamma$ value is lower than other values reported in high gradient streams by Mao et al. [2008] (0.79 and 0.64) and Yager et al. [2012a] $(\gamma=0.62)$ and is also lower than data compiled by Parker [2008], which shows a mean value of $\gamma=0.79 \pm 0.16 \quad$ (mean \pm standard deviation) on modest sloping gravel-bed streams $(S=1-1.5 \%)$. This low $\gamma$ value indicates a reduced influence of hiding effects in steep streams and suggests that small grains are relatively easier to transport than large grains, ultimately leading to the preference of mobilization of distinct size classes during a given flow event. A preference to transport smaller grains (i.e., $D / k_{s}<1$ ) is supported by our observations of particle transport distances (Figure 10) and partial transport (Figure 9) and leads to increased $\tau_{*_{c}}$ values compared to assuming that the median grain size will be mobilized (i.e., $D / k_{s}=1$ ).

\subsubsection{Summary of Dominant Effects on Initial Motion}

[56] We examined the net effect of form drag, slopedependent hydraulics, bed patchiness, and grain hiding by calculating the ratio of the field-estimated $\left(\tau_{*}{ }_{c \text {-field }}\right)$ to model-predicted $\left(\tau_{*_{c-\text { model }}}\right)$ critical Shields stress (Figure 15). Effects which increase critical Shields stress result in $\tau_{*_{c \text {-field }}} / \tau_{*_{c \text {-model }}}>1$, while effects which decrease critical Shields stress result in $\tau_{*_{c} \text {-field }} / \tau_{*_{c} \text {-model }}<1$. We took the median $\tau *_{c \text {-field }} / \tau_{*_{c} \text {-model }}$ value as a proxy for the general degree to which a specific effect increases or decreases critical Shields stress according to the model. Slope-dependent hydraulics and form drag generally led to increased critical Shields stress compared to what is expected without these effects (median $\tau *_{c \text {-field }} / \tau_{*_{c \text {-model }}}$ of 2.9 and 1.8, respectively). Size-sorted patches caused reduction of critical Shields stress by a factor of 2.3 (median $\tau_{*_{c} \text {-field }} / \tau_{*_{c-\text { model }}}$ of 0.44 ) compared to what is expected without patches. For our field data, grain hiding did not cause a substantial change in the median critical Shields 
stress compared to what is expected without grain hiding, because the effect is only significant at the tails of the distribution (i.e., $D / k_{s} \neq 1$ ). However, grain hiding is statistically significant by both the Kolmogorov-Smirnov (Figure 13d) and $t$ test (Figure 14) when examining the entire data set.

\section{Discussion}

\subsection{Controls on Incipient Motion, Patch Evolution, and Partial Transport}

[57] We found that accounting for the effects of slopedependent hydraulics, grain hiding, and local variation in grain size and bed roughness due to sediment-size-sorted patches yielded critical Shields stress predictions that matched our field data within a factor of $\sim 3$. Accounting for slope-dependent hydraulics and local roughness variation due to patches appeared to have the strongest controls on predicting incipient motion for our field data for grains with $D / k_{s} \approx 1$, although, these effects have opposite influences on critical Shields stress (Figure 15).

[58] The influence of slope-dependent hydraulics generally resulted in increased critical Shields stress as shown by our field data to model comparison (Figures 13 and 15) as well as other field data [e.g., Mueller et al., 2005; Mao et al., 2008] and theory [e.g., Lamb et al., 2008a; Recking, 2009; Ferguson, 2012]. This heightened $\tau_{*_{c}}$ may help explain why standard sediment-transport equations tend to over-predict bedload flux by greater than an order of magnitude in steep streams [Yager et al., 2012a].

[59] The presence of size-sorted patches generally led to decreased critical Shields stresses compared to what is expected without patches in the streams examined here. This is likely due to the fact that local sediment sorting allows for patches of finer material and reduces the influence of grain hiding [e.g., Paola and Seal, 1995], suggesting that sediment transport is sensitive to local variations in bed roughness (which can induce complex feedbacks between bed topography and shear stress distribution [Nelson et al., 2009; Nelson et al., 2010]). Using reach-averaged roughness rather than local roughness can result in erroneous predictions of no sediment transport for cases when sediment transport does occur, thus impacting sediment routing and habitat availability predictions (Figure 13c). While there have been several studies attempting to quantify slopedependent hydraulic effects [e.g., Nikora et al., 2001; Lamb et al., 2008a; Recking, 2009] and grain hiding [e.g., Einstein, 1950; Egiazaroff, 1965; Wiberg and Smith, 1987; Kirchner et al., 1990], no such quantification exists for predicting sediment-patch locations in mountain streams, although progress has been made for low-gradient channels [Nelson et al., 2010]. Grain hiding within patches can both increase or decrease critical Shields stress depending on if $D / k_{s}$ is less than or greater than unity, respectively (Figure 14).

[60] Form drag on immobile elements likely exists in the Elder Creek tributaries examined here and has been shown to influence flow hydraulics and sediment transport in other rivers [e.g., Buffington and Montgomery, 1999; Ferguson, 2007; Rickenmann and Recking, 2011; Yager et al., 2012a]; however, correction for form drag on immobile elements did not appear to greatly improve model predictions of critical Shields stress compared to our field data, which may indicate that form drag has a smaller influence on incipient motion than the other effects examined.

[61] Accounting for local roughness length scales, slopedependent hydraulics, and grain hiding allows predictions for specific areas of the bed (i.e., specific patches) and grain-size distributions (i.e., specific grain sizes within a patch) which will be active as a function of bed shear stress during modest discharge events. In steep streams with distinct patches of different size sediment and where grain hiding is important (i.e., $\gamma<1$ ), such calculations result in predictions of both reach-wide partial transport of sediment and partial transport within individual patches. Reach-wide partial transport is common in moderate gradient and steep gravel-bed streams [Hassan and Church, 2001; Church and Hassan, 2002; Gomi and Sidle, 2003; Haschenburger and Wilcock, 2003; Mao and Lenzi, 2007; Thompson and Croke, 2008; Yager et al., 2012b] and was observed in the tributaries examined here (Figure 9). Partial transport within patches has been documented by Yager et al. [2012b] in two high-gradient streams $(S=5 \%$ and $9.8 \%)$ and is also observed for patches in this study. Both reach-wide and patch-scale partial transport of sediment during moderate discharge events in steep streams may be a result of grain hiding and the presence of distinct size-sorted patches across the bed.

[62] In addition to influencing grain entrainment, patches likely also play a role in grain deposition. We observed near constant median grain sizes of patches over the monitoring period, suggesting mobilized grains were replaced by sediment of similar sizes (Figure 8). This process of grain replacement with unchanging patch grain-size distribution and areal extent has been observed previously in streams up to $S=9.8 \%$ [Yager et al., 2012b] and other lower gradient gravel-bed streams [Dietrich et al., 2006; Yuill et al., 2010], but has not been documented in channels with slopes up to $37 \%$ examined here. Such observations lend support to arguments for patch evolution via feedbacks between bed topography, bed shear stress, and sediment transport [Nelson et al., 2009; Nelson et al., 2010].

[63] During very large floods, the coupling between local roughness, patch evolution, and sediment transport is likely disrupted via reorganization of the channel bed and resetting of the local roughness length scale. Studies in the Erlenbach River, Switzerland $(S=9.8 \%)$, for example, showed partial transport under modest flow conditions, and bed reorganization with boulder mobilization and the destruction of step-pool morphology in extreme events (discharges with 25-50 year recurrence intervals) [Turowski et al., 2009; Yager et al., 2012b]. This also has been documented in other moderate to high gradient rivers where mobilization of grains greater than the median grain size only occurs during floods of recurrence intervals greater than 5 to 10 years [Haschenburger and Wilcock, 2003; Mao and Lenzi, 2007; Thompson and Croke, 2008]. We expect to find bed reorganization and mobilization of all grains in very large floods in the tributaries examined here, although it is possible that large grains are only moved in debris flow events and subsequent fluvial action may undermine these grains and abrade them in place.

\subsection{Influence of Fluvial Processes in Steep Streams on Landscape Evolution}

[64] Data on incipient motion and patch development in high gradient streams are rare, and this is the first attempt, 
to our knowledge, to document field-based critical Shields values for streams with $S>14 \%$. While it is often assumed that steep streams are dominated by debris flow processes [e.g., Stock and Dietrich, 2003; Stock and Dietrich, 2006], we found that fluvial processes active at moderate gradient gravel-bed streams $(S \approx 1-5 \%)$ occurred in the steep streams examined here $(S>5 \%)$; although often only a select fraction of the bed was mobilized as the reaches experienced partial transport of sediment. These results show that fluvial processes play a key role in transporting gravel downstream during storms in very steep channels (at least up to $37 \%$ slope), with implications for sediment routing models and habitat assessment for aquatic organisms (which often have distinct relationships with the local substrate [e.g., Lisle, 1989]).

[65] While our results show that fluvial sediment transport occurs, it is difficult to assess the relative importance of fluvial versus debris flow processes over landscape evolution timescales in our study area. Almost all of the tributaries joining Elder Creek are incised into debris flow fans, which often have boulders larger than $1 \mathrm{~m}$ in diameter. These entrenched channels with imbricated cobbles suggest that fluvial processes entrain and transport material from debris flow deposits (and gravel entering the river between debris flow events) to lower gradient streams within the Elder Creek watershed. Fluvial and debris flow processes likely occur over different time scales in the tributaries monitored here, with fluvial mobilization of gravel on an annual basis and intermittent debris flow activity occurring over centuries to millennia [Scheingross et al., 2008].

\section{Conclusions}

[66] We monitored mobilization of sediment in five small (drainage areas of 0.04 to $2 \mathrm{~km}^{2}$ ) and steep $(S=5-37 \%$ ) tributaries of Elder Creek, CA. Our results show that smaller grains tended to travel further distances than larger grains, and sediment patches tended to maintain near-constant median grain sizes temporally. There was partial transport of sediment both reach-wide and within individual patches, indicating that large portions of the bed (usually composed of large grains) are immobile during modest flow conditions. Flow resistance was similar to that predicted by Ferguson [2007], where the Darcy-Weisbach friction factor increased with increasing relative roughness. Using three different methods to calculate form drag on immobile elements, we found that form drag on immobile structures accounted for approximately $80 \%$ of the total bed stress, with the remaining $20 \%$ of the total bed stress available for sediment transport. Field-estimated values of the Shields stress at incipient motion range from 0.02 to 2 and agree with theoretical predictions within a factor of $\sim 3$ when slope-dependent changes in flow hydraulics, sedimentsize-sorted patches, and grain hiding effects were taken into account. We saw no improvement of model predictions when including the effect of form drag, suggesting that form drag influences critical Shields stress less than the other effects examined. Slope-dependent hydraulics and the presence of patches had the strongest (although opposite) influence on incipient motion, resulting in increased and decreased $\tau_{*_{c}}$, respectively. For grains smaller or larger than the roughness length scale, grain hiding influenced incipient motion. Larger grains tended to move at higher shear stresses leading to partial transport both within patches and reach-wide.

[67] Our results suggest that accounting for the effects of local variation in roughness due to patches, slopedependent hydraulics, and grain hiding allows for prediction of both specific patches that will be active and for the approximate grain-size distribution mobilized from patches as a function of bed shear stress. Such predictions offer an improvement over traditional methods (i.e., assuming $\tau_{*_{c}} \approx 0.045$ and that all grains are mobilized at the same time) and should be useful for sedimentation engineering, stream restoration efforts, and predictions of aquatic habitat availability. In very steep channels, often considered to be dominated by debris flows, our results show that fluvial sediment transport occurs even for modest flows with implications for sediment routing and landscape evolution.

\section{Notation}

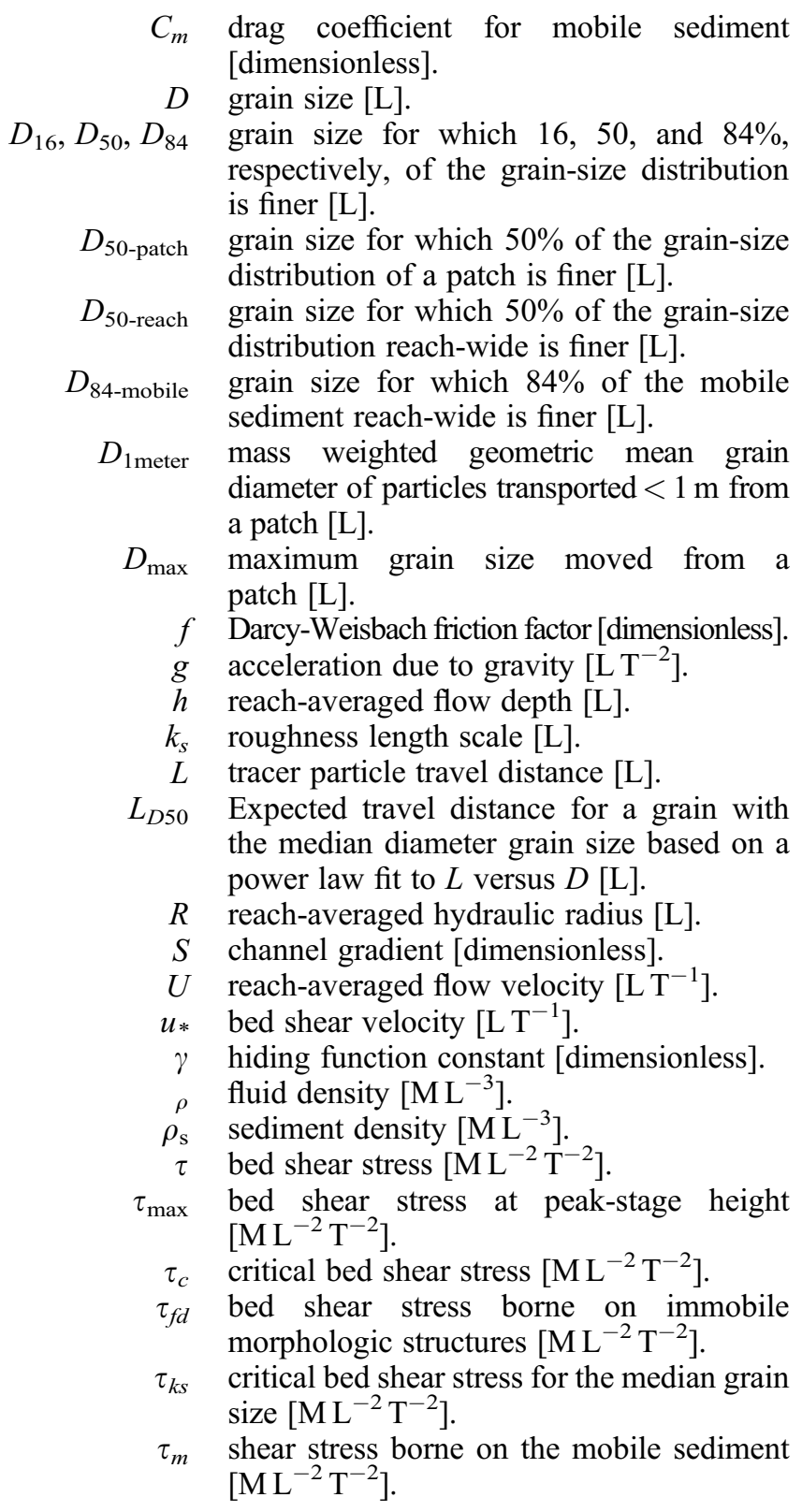




\section{$\tau_{T} \quad$ total bed shear stress $\left[\mathrm{ML}^{-2} \mathrm{~T}^{-2}\right]$. \\ $\tau_{*_{c}} \quad$ critical bed Shields stress [dimensionless]. \\ $\tau_{* \text {-field }}$ field-estimated values of critical bed Shields stress [dimensionless].

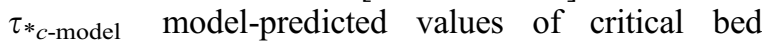 Shields stress [dimensionless].}

[68] Acknowledgments. Support for this work came from the National Center for Earth-Surface Dynamics, NASA BioMars Grant to W.E.D., the Charles H. Ramsden Endowed Fund to J.S.S., and NSF EAR-0922199 grant to M.P.L. J.S.S. was partially supported by a NSF Graduate Research Fellowship. We thank Toby Minear for assistance with terrestrial LiDAR scanning. Airborne laser swath mapping data were provided by the National Center for Airborne Laser Mapping. Jonathan Perkins, Peter Nelson, Kathleen Swanson, Jasper Oshun, Eric Kleinsasser, Alessandro Uccelli, Sam Peach, Ben Mackey, Colin Phillips, Evan Scheingross, Matt Stuckey, and Clark Winchell assisted with field work. We thank Peter Steel for facilitating land access and logistical support at the University of California's Angelo Coast Range Reserve. This manuscript greatly benefited from constructive reviews by Dieter Rickenmann, André Zimmermann, and an anonymous reviewer, as well as editing by Alexander Densmore and John Pitlick.

\section{References}

Andrews, E. D. (1983), Entrainment of gravel from naturally sorted riverbed material, Geol. Soc. Am. Bull., 94(10), 1225-1231.

Ashida, K., and M. Bayazi (1973), Initiation of motion and roughness of flows in steep channels, Int. Assoc. Hydraul. Res. Proc. 15th Congr., Istanbul, Turkey, 1, 475-484.

Bathurst, J. C., H. H. Cao, and W. H. Graf (1984), Hydraulics and sediment transport in a steep flume. Data from the EPFL study, Rep. 64, Institute of Hydrology, Wallingford, Oxon, England.

Benda, L., M. A. Hassan, M. Church, and C. L. May (2005), Geomorphology of steepland headwaters: The transition from hillslopes to channels, J. Am. Water Resour. Assoc., 41(4), 835-851.

Brayshaw, A. C., L. E. Frostick, and I. Reid (1983), The hydrodynamics of particle clusters and sediment entrainment in coarse alluvial channels, Sedimentology, 30(1), 137-143, doi:10.1111/j.1365-3091.1983. tb00656.X.

Buffington, J. M., and D. R. Montgomery (1997), A systematic analysis of eight decades of incipient motion studies, with special reference to gravel-bedded rivers, Water Resour. Res., 33(8), 1993-2029, doi:10.1029/ 96WR03190.

Buffington, J. M., and D. R. Montgomery (1999), Effects of hydraulic roughness on surface textures of gravel-bed rivers, Water Resour. Res., 35(11), 3507-3521, doi:10.1029/1999WR900138.

Buffington, J. M., D. R. Montgomery, and H. M. Greenberg (2004), Basinscale availability of salmonid spawning gravel as influenced by channel type and hydraulic roughness in mountain catchments, Can. J. Fish. Aquat. Sci., 61(11), 2085-2096, doi:10.1139/f04-141.

Bunte, K., and S. R. Abt (2001), Sampling surface and subsurface particlesize distributions in wadable gravel- and cobble-bed streams for analyses in sediment transport, hydraulics, and streambed monitoring, Rep. RMRSGTR-74, United States Department of Agriculture, Rocky Mountain Research Station, Fort Collins, CO.

Calkins, D., and T. Dunne (1970), A salt tracing method for measuring channel velocities in small mountain streams, J. Hydrol., 11, 379-392.

Church, M., and M. A. Hassan (1992), Size and distance of travel of unconstrained clasts on a streambed, Water Resour. Res., 28(1), 299-303, doi:10.1029/91WR02523.

Church, M., and M. A. Hassan (2002), Mobility of bed material in Harris Creek, Water Resour. Res., 38(11), 1237, doi:10.1029/2001WR000753.

Comiti, F., and L. Mao (2012), Recent advances in the dynamics of steep channels, in Gravel-Bed Rivers: Processes, Tools, Environments, edited by M. Church, P. M. Biron, and A. G. Roy, Wiley-Blackwell, Chichester, 353-377.

Cui, Y. T., and G. Parker (2005), Numerical model of sediment pulses and sediment-supply disturbances in mountain rivers, J. Hydraul. Eng.-Asce, 131(8), 646-656, doi:10.1061/(asce)0733-9429(2005)131:8(646).

Day, T. J. (1977a), Field procedures and evaluation of a slug dilution gauging method in mountain streams, J. Hydrol. New Zealand, 16(2), $113-133$.

Day, T. J. (1977b), Observed mixing lengths in mountain streams, J. Hydrol., 35(1-2), doi:10.1016/0022-1694(77)90081-6.

Dietrich, W. E., D. G. Bellugi, L. S. Sklar, J. D. Stock, A. M. Heimsath, and J. J. Roering (2003), Geomorphic transport laws for predicting landscape form and dynamics, in Prediction in Geomorphology, edited by P. R. Wilcock, and R. Iverson, American Geophysical Union, Washington DC, 103-132.

Dietrich, W. E., P. A. Nelson, E. Yager, J. G. Venditti, M. P. Lamb, and L. Collins (2006), Sediment patches, sediment supply, and channel morphology, in River, Coastal and Estuarine Morphodynamics, RCEM 2005 , edited by G. Parker, and M. H. Garcia, pp. 79-90, Taylor and Francis/Balkema, The Netherlands.

Egiazaroff, I. V. (1965), Calculation of non-uniform sediment concentrations, J. Hydraul. Eng., 91(4), 225-248.

Einstein, H. A. (1950), The bedload function for sediment transport in open channel flows, Rep. Technical Bulletin no. 1026, US Department of Agriculture, Washington DC.

Elder, K., R. Kattelmann, and R. Ferguson (1990), Refinements in dilution gauging for mountain streams, in Hydrology in mountainous regions, I-hydrological measurements; the water cycle, Proceedings of two Lausanne Symposia, IAHS Publication no. 193.

Ferguson, R. (2007), Flow resistance equations for gravel- and boulder-bed streams, Water Resour. Res., 43, W05427, doi:10.1029/2006WR005422.

Ferguson, R. I. (2012), River channel slope, flow resistance, and gravel entrainment thresholds, Water Resour. Res., 48, W05517, doi:10.1029/ 2011WR010850.

Ferguson, R. I., and S. J. Wathen (1998), Tracer-pebble movement along a concave river profile: Virtual velocity in relation to grain size and shear stress, Water Resour. Res., 34(8), 2031-2038, doi:10.1029/98WR01283.

Fuller, T. K., L. A. Perg, J. K. Willenbring, and K. Lepper (2009), Field evidence for climate-driven changes in sediment supply leading to strath terrace formation, Geology, 37, 467-470, doi:10.1130/g25487a.1.

Gomi, T., and R. C. Sidle (2003), Bed load transport in managed steepgradient headwater streams of southeastern Alaska, Water Resour. Res., 39(12), 1336, doi:10.1029/2003WR002440.

Grant, G. E., F. J. Swanson, and M. G. Wolman (1990), Pattern and origin of stepped-bed morphology in high-gradient streams, western Cascades, Oregon, Geol. Soc. Am. Bull., 102(3), 340-352, doi:10.1130/0016-7606 (1990) $102<0340$ :paoosb > 2.3.co;2.

Haschenburger, J. K., and P. R. Wilcock (2003), Partial transport in a natural gravel bed channel, Water Resour. Res., 39(1), 1020, doi:10.1029/ 2002WR001532.

Hassan, M. A., and M. Church (2001), Sensitivity of bed load transport in Harris Creek: Seasonal and spatial variation over a cobble-gravel bar, Water Resour. Res., 37(3), 813-825, doi:10.1029/2000WR900346.

Hodge, R. A., T. B. Hoey, and L. S. Sklar (2011), Bed load transport in bedrock rivers: The role of sediment cover in grain entrainment, translation, and deposition, J. Geophys. Res., 116, F04028, doi:10.1029/2011JF002032.

Holmes, R. R., Jr., P. J. Terrio, M. A. Harris, and P. C. Mills (2001), Introduction to field methods for hydrologic and environmental studies, US Geological Survey Open-file report 01-50, Urbana, Illinois.

Hudson, R., and J. Fraser (2005), Introduction to salt dilution gauging for streamflow measurement part IV: The mass balance (or dry injection) method, Streamline Watershed Manag. Bull., 9(1), 6-12.

Jayko, A. S., M. C. Blake, R. J. McLaughlin, H. N. Ohlin, S. D. Ellen, and H. M. Kelsey (1989), Reconnaissance geologic map of the Covelo 30- by 60-minute quadrangle, northern California, Rep. Miscellaneous Field Studies Map MF-2001, scale 1:100,000, United States Geological Survey, Washington, DC.

Kirchner, J. W., W. E. Dietrich, F. Iseya, and H. Ikeda (1990), The variability of critical shear-stress, friction angle, and grain protrusion in water-worked sediments, Sedimentology, 37(4), 647-672.

Lamb, M. P., W. E. Dietrich, and J. G. Venditti (2008a), Is the critical shields stress for incipient sediment motion dependent on channel-bed slope?, J. Geophys. Res., 113, F02008, doi:10.1029/2007JF000831.

Lamb, M. P., W. E. Dietrich, and L. S. Sklar (2008b), A model for fluvial bedrock incision by impacting suspended and bed load sediment, J. Geophys. Res., 113, F03025, doi:10.1029/2007JF000915.

Lenzi, M. A. (2004), Displacement and transport of marked pebbles, cobbles and boulders during floods in a steep mountain stream, Hydrol. Process., 18(10), 1899-1914, doi:10.1002/hyp.1456.

Lenzi, M. A., L. Mao, and F. Comiti (2006), When does bedload transport begin in steep boulder-bed streams?, Hydrol. Process., 20(16), 3517-3533, doi:10.1002/hyp.6168.

Lisle, T. E. (1989), Sediment transport and resulting deposition in spawning gravels, north coastal California, Water Resour. Res., 25(6), 1303-1319, doi:10.1029/WR025i006p01303.

Mao, L., and M. A. Lenzi (2007), Sediment mobility and bedload transport conditions in an alpine stream, Hydrol. Process., 21(14), 1882-1891, doi:10.1002/hyp.6372.

Mao, L., G. P. Uyttendaele, A. Iroume, and M. A. Lenzi (2008), Field based analysis of sediment entrainment in two high gradient streams located in alpine and Andine environments, Geomorphology, 93(3-4), 368-383, doi:10.1016/j.geomorph.2007.03.008. 


\section{SCHEINGROSS ET AL.: GRAVEL MOBILIZATION IN STEEP CHANNELS}

Marcus, W. A., K. Roberts, L. Harvey, and G. Tackman (1992), An evaluation of methods for estimating Mannings-n in small mountain streams, Mt. Res. Dev., 12(3), 227-239.

Mast, M. A., and D. W. Chow (2000), Environmental characteristics and water-quality of hydrologic benchmark network stations in the Western United States, Rep. 1173-D, United States Geological Survey, Washington, DC.

Millar, R. G. (1999), Grain and form resistance in gravel-bed rivers, J. Hydraul. Res., 37(3), 303-312.

Mizuyama, T. (1977), Bedload transport in steep channels, Ph.D. dissertation thesis, Kyoto University, Kyoto, Japan.

Montgomery, D. R. (2004), Geology, geomorphology, and the restoration ecology of salmon, GSA Today, 14(11), 4-12.

Montgomery, D. R., and J. M. Buffington (1997), Channel-reach morphology in mountain drainage basins, Geol. Soc. Am. Bull., 109(5), 596-611.

Moore, R. D. (2003), Introduction to salt dilution gauging for streamflow measurement: Part 1, Streamline Watershed Manag. Bull., 7(4), 20-23.

Mueller, E. R., J. Pitlick, and J. M. Nelson (2005), Variation in the reference shields stress for bed load transport in gravel-bed streams and rivers, Water Resour. Res., 41, W04006, doi:10.1029/2004WR003692.

Nelson, P. A., W. E. Dietrich, and J. G. Venditti (2010), Bed topography and the development of forced bed surface patches, J. Geophys. Res., 115, F04024, doi:10.1029/2010JF001747.

Nelson, P. A., J. G. Venditti, W. E. Dietrich, J. W. Kirchner, H. Ikeda, F. Iseya, and L. S. Sklar (2009), Response of bed surface patchiness to reductions in sediment supply, J. Geophys. Res., 114, F02005, doi:10.1029/ 2008JF001144.

Nikora, V., D. Goring, I. McEwan, and G. Griffiths (2001), Spatially averaged open-channel flow over rough bed, J. Hydraul. Eng.-Asce, 127(2), doi:10.1061/(asce)0733-9429(2001)127:2(123).

Nitsche, M., D. Rickenmann, J. M. Turowski, A. Badoux, and J. W. Kirchner (2011), Evaluation of bedload transport predictions using flow resistance equations to account for macro-roughness in steep mountain streams, Water Resour. Res., 47, W08513, doi:10.1029/2011WR010645.

Paola, C., and R. Seal (1995), Grain-size patchiness as a cause of selective deposition and downstream fining, Water Resour. Res., 31(5), 1395-1407, doi:10.1029/94WR02975.

Parker, G. (2008), Transport of gravel and sediment mixtures, in Sedimentation engineering processes, measurements, modeling, and practice, edited by M. H. Garcia, American Society of Civil Engineers.

Prancevic, J. P., M. P. Lamb, and B. M. Fuller (2011), Assessing the slope dependency of the critical shields stress in very steep streams using laboratory flume experiments, abstract EP21C-0708, paper presented at 2011 Fall Meeting, AGU, San Francisco, Calif. 5-9 Dec.

Recking, A. (2009), Theoretical development on the effects of changing flow hydraulics on incipient bed load motion, Water Resour. Res., 45, W04401, doi:10.1029/2008WR006826.

Rickenmann, D., and A. Recking (2011), Evaluation of flow resistance in gravel-bed rivers through a large field data set, Water Resour. Res., 47 W07538, doi:10.1029/2010WR009793.

Rouse, H. (1936), Discharge characteristics of the free overfall, Civ. Eng., $6(4), 257-260$

Scheingross, J. S., J. K. Willenbring, and W. E. Dietrich (2008), Erosion rates and debris flow history reconstruction: A comparison of carbon and cosmogenic nuclide dating techniques, Eos Trans. AGU, 89(53), Fall Meet. Suppl., Abstract H51D-0852.
Shields, A. (1936), Anwendung der aehnlichkeitsmechanik und der turbulenzforschung auf die geschiebebewegung, Mitt. Preuss. Versuchsanst. Wasserbau Schiffbau, 26(26)

Sklar, L. S., and W. E. Dietrich (2004), A mechanistic model for river incision into bedrock by saltating bed load, Water Resour. Res., 40, W06301, doi:10.1029/2003WR002496.

Stock, J., and W. E. Dietrich (2003), Valley incision by debris flows: Evidence of a topographic signature, Water Resour. Res., 39(4), 1089, doi:10.1029/2001WR001057.

Stock, J. D., and W. E. Dietrich (2006), Erosion of steepland valleys by debris flows, Geol. Soc. Am. Bull., 118(9-10), 1125-1148, doi:10.1130/b25902.1.

Thompson, C., and J. Croke (2008), Channel flow competence and sediment transport in upland streams in southeast Australia, Earth Surf. Process. Landforms, 33(3), 329-352, doi:10.1002/esp.1558.

Tsai, V. C., B. Minchew, M. P. Lamb, and J.-P. Ampuero (2012), A physical model for seismic noise generation from sediment transport in rivers, Geophys. Res. Lett., 39, L02404, doi:10.1029/2011GL050255.

Tucker, G. E., and G. R. Hancock (2010), Modelling landscape evolution, Earth Surf. Process. Landforms, 35(1), 28-50, doi:10.1002/esp.1952.

Turowski, J. M., E. M. Yager, A. Badoux, D. Rickenmann, and P. Molnar (2009), The impact of exceptional events on erosion, bedload transport and channel stability in a step-pool channel, Earth Surf. Process. Landforms, 34(12), 1661-1673, doi:10.1002/esp.1855.

Whipple, K. X. (2004), Bedrock rivers and the geomorphology of active orogens, Annu. Rev. Earth Planet. Sci., 32, 151-185, doi:10.1146 annurev.earth.32.101802.120356.

Wiberg, P. L., and J. D. Smith (1985), A theoretical-model for saltating grains in water, J. Geophys. Res., 90(NC4), 7341-7354, doi:10.1029/ JC090iC04p0734

Wiberg, P. L., and J. D. Smith (1987), Calculations of the critical shearstress for motion of uniform and heterogeneous sediments, Water Resour. Res., 23(8), 1471-1480, doi:10.1029/WR023i008p01471.

Wiberg, P. L., and J. D. Smith (1991), Velocity distribution and bed roughness in high-gradient streams, Water Resour. Res., 27(5), 825-838, doi:10.1029/90WR02770.

Wiele, S. M., P. R. Wilcock, and P. E. Grams (2007), Reach-averaged sediment routing model of a canyon river, Water Resour. Res., 43, W02425doi:10.1029/2005WR004824.

Wilcock, P. R. (1992), Flow competence-A criticism of a classic concept, Earth Surf. Process. Landforms, 17(3), 289-298, doi:10.1002/ esp. 3290170307.

Wilcock, P. R. (1997), Entrainment, displacement and transport of tracer gravels, Earth Surf. Process. Landforms, 22(12), 1125-1138,

Yager, E. M., J. W. Kirchner, and W. E. Dietrich (2007), Calculating bed load transport in steep boulder bed channels, Water Resour. Res., 43, W07418, doi:10.1029/2006WR005432.

Yager, E. M., W. E. Dietrich, J. W. Kirchner, and B. W. McArdell (2012a), Prediction of sediment transport in step-pool channels, Water Resour. Res., 48, W01541, doi:10.1029/2011WR010829.

Yager, E. M., W. E. Dietrich, J. W. Kirchner, and B. W. McArdell (2012b), Patch dynamics and stability in steep, rough streams, J. Geophys. Res. 117, F02010, doi:10.1029/2011JF002253.

Yuill, B., M. Nichols, and E. Yager (2010), Coarse bed material patch evolution in low-order, ephemeral channels, Catena, 81(2), 126-136, doi:10.1016/j.catena.2010.02.002

Zar, J. H. (1999), Biostatistical Analysis, 4th ed., pp. 475-483, Prentice Hall, Upper Saddle River, New Jersey. 